\title{
Experiência em serviços e segmentação pela renda em uma cooperativa de crédito
}

\author{
Experience in services and segmentation by income in a credit cooperative
}

\author{
Expérience des services et segmentation par revenu sur un credit cooperatif \\ Experiencia en servicios y segmentación por la renta en una cooperativa de \\ crédito
}

\author{
Viviane Sotoriva Cappellesso ${ }^{1}$ \\ June Alisson Westarb $\mathrm{Cruz}^{1}$ \\ Tomas Sparano Martins ${ }^{2}$
}

Recebido em 06/07/2017; revisado e aprovado em 14/11/2017 ; aceito em 16/12/2017

DOI: http://dx.doi.org/10.20435/inter.v0i0.1650

\begin{abstract}
Resumo: O presente artigo refere-se a um estudo de caso em uma cooperativa de crédito segmentada nos profissionais da saúde. A pesquisa objetivou analisar a experiência em serviço da cooperativa com seu quadro social, segmentado pela renda. O estudo pode ser descrito como uma pesquisa exploratória e descritiva de caráter quantitativo com corte transversal obtida através de dados primários e secundários que resultaram no grau de satisfação, lealdade e boca a boca do quadro social.
\end{abstract}

Palavras-chave: experiência em serviços; renda; cooperativa; crédito.

Abstract: The present paper refers to a case study in a credit cooperative segmented in health professionals. The research aimed to analyze the experience in service of the cooperative with its membership, segmented by income. The study can be described as an exploratory and descriptive quantitative cross-sectional study obtained through primary and secondary data that has resulted in satisfaction, loyalty and mouth-to-mouth membership.

Keywords: experience in services; income; cooperativa; credit.

Résumé: II fait référence à une étude de cas dans une caisse ciblée dans la main-d’œuvre de la santé. La recherche visait à analyser l'expérience de service de la coopérative avec ses membres, segmentée en fonction du revenu. L'étude peut être décrit comme un caractère quantitatif recherche descriptive et exploratoire obtenu en coupe transversale à travers les données primaires et secondaires qui ont abouti à la satisfaction et la fidélité et la parole de l'adhésion de la bouche.

Mots-clés: expérience dans les services; le revenu; coopérative; crédit.

Resumen: El presente se refiere a un estudio de caso en una cooperativa de crédito segmentada en los profesionales de la salud. La investigación objetivó analizar la experiencia en servicio de la cooperativa con su cuadro social, segmentado por la renta. El estudio puede ser descrito como una investigación exploratoria y descriptiva de carácter cuantitativo con corte transversal obtenido a través de datos primarios y secundarios que resultaron en el grado de satisfacción, lealtad y boca a boca del cuadro social.

Palabras clave: experiencia en servicios; renta; cooperativa; crédito.

\section{INTRODUÇÃO}

A sociedade brasileira vem passando por momentos intrigantes em sua história, os quais forçam as pessoas e as instituições a buscarem diferentes configurações para lidarem com seus esforços estratégicos, financeiros e de capital. Nesse contexto, as organizações cooperativas, conceituadas como sociedades de pessoas que têm forma e natureza jurídica próprias, constituídas para prestação de serviços aos seus membros cooperados, emergem com regime

\footnotetext{
1 Pontifícia Universidade Católica do Paraná (PUCPR), Curitiba, Paraná, Brasil.

2 Universidade Federal do Paraná (UFPR), Curitiba, Paraná, Brasil,
} 
jurídico próprio, instituído pela Lei n. 5.764, de 16 de dezembro de 1971, como uma alternativa societária em busca de objetivos individuais e coletivos.

As cooperativas de crédito, no Brasil, são equiparadas às instituições financeiras, conforme o art. 18 da Lei n. 4.595, de 31 de dezembro de 1964, devendo ser autorizadas e regulamentadas pelo Banco Central do Brasil. Assim, concorrem com todas as empresas e organizações que prestam serviços financeiros. Dessa forma, o setor como um todo, e também de maneira específica, é considerado muito competitivo. Destarte, organizações que competem no setor devem buscar desenvolver estratégias de diferenciação que sejam valorizadas pelos clientes. Como os cinco grandes bancos brasileiros (Banco do Brasil, Caixa Econômica Federal, Itaú, Bradesco e Santander) se posicionam baseados em seu tamanho e capilaridade, ou seja, visam atender grande diversidade e quantidade de clientes em grandes áreas geográficas, há uma oportunidade para outras instituições no setor que se posicionarem com base em outro diferencial competitivo que não seja o porte da organização, como, por exemplo, qualidade em serviço, imagem da marca ou experiência em serviço.

Segundo Holbrook e Hirschman (1982), a experiência em serviço é uma forma de diferenciação, pois é uma ocorrência pessoal, fundada na interação com produtos e serviços consumidos, que visam criar experiências superiores aos consumidores para deles obter a lealdade e a fidelidade (VERHOEF et al., 2009). Segundo Schembri (2006), a experiência em serviço deveria ser o principal determinante da avaliação da qualidade dos serviços.

Assim, uma organização prestadora de serviços que busca vantagem competitiva sustentável em um setor competitivo, como o de serviços financeiros com base em atendimento, nível e qualidade de serviços, deve constantemente medir a satisfação dos cooperados com base na experiência deles percebida em relação aos serviços prestados.

Diante de tal contexto e motivado pela provocação de medir a experiência em serviços do quadro social em uma cooperativa de crédito, a presente pesquisa tem como objetivo central avaliar a percepção dos cooperados com relação à experiência em serviços em uma cooperativa de crédito, segmentados pela renda. Para tanto, o artigo está estruturado nas seguintes sessões: Introdução, Abordagem Teórica, Abordagem Metodológica, Apresentação e Análise dos Dados e Considerações Finais.

\section{ABORDAGEM TEÓRICA}

Esta seção tem como objetivo estabelecer a relação teórica dos principais temas da pesquisa, compreendendo a perspectiva geral do cooperativismo de crédito do Brasil em seu contexto histórico e as principais características de serviços e experiência em serviços.

\subsection{Cooperativismo de crérito no Brasil: contexto histórico}

No Brasil, a primeira cooperativa de crédito foi fundada em 28 de dezembro de 1902, para colonos alemães da região na cidade de Nova Petrópolis (RS), a Caixa de Economia e Empréstimos Amstad, posteriormente batizada de Caixa Rural de Nova Petrópolis (PINHO, 2004). Essa cooperativa, do tipo Raiffeisen, continua em atividade até hoje sob a denominação Sicredi Pioneira/RS. Entre os anos de 1902 e 1964, ainda surgiriam 66 cooperativas de crédito do tipo Raiffeisen no Rio Grande do Sul (PINHO, 2004). A partir dessa iniciativa, surgiram inúmeras outras 
cooperativas da espécie que, diante do foco predominantemente rural, eram subordinadas ao Ministério da Agricultura.

Dados do Banco Central do Brasil (2015) davam conta da existência de 1.094 Cooperativas Financeiras no Brasil, que administravam ativos totais de $\mathrm{R} \$ 180$ bilhões. Somando-se a esse valor os ativos do Banco Sicredi S.A. e do Bancoob, têm-se ativos totais de $\mathrm{R} \$ 237$ bilhões no ramo do crédito, representando uma participação no mercado de $2,84 \%$ no total de ativos do mercado financeiro brasileiro e dando às cooperativas de crédito a 6 a posição no ranking das maiores instituições financeiras do país. Ainda, conforme Luciano Fantin, CEO da Unicred Brasil (apud BELMONTE, 2016), as operações de crédito totais atingiram R\$ 96 bilhões, representando 2,85\% do total do Sistema Financeiro Nacional (SFN), e os depósitos de R\$ 115 bilhões representavam $5,44 \%$.

O documento do Banco Central também aponta que o percentual de participação das cooperativas de crédito aumentou em relação ao Sistema Financeiro Nacional (SFN). Em ativos totais, os R\$154,1 bilhões corresponderam a 1,87\% do SFN, os R\$ 83,6 bilhões da carteira de crédito equivalem a 2,41\% e, nos depósitos, o percentual é de 4,26\% com R\$ 90,9 bilhões. Segundo Relatório Consolidado da Organização das Cooperativas do Brasil (OCB), no final do exercício de 2016, o cooperativismo de crédito brasileiro possuía 8,9 milhões de associados, e esse número está em significativo crescimento (OCB, 2017).

\subsection{Experiência em serviço}

As operações de serviços assumiram elevada importância no mundo contemporâneo com o avanço do interesse acadêmico pelo assunto (CHASE; APTE, 2007). Heineke e Davis (2007) destacam a importância do tema ao afirmarem a interdependência entre bens e serviços, ou seja, de que a produção e a venda de produtos estão geralmente associadas a algum tipo de prestação de serviço.

Pine Il e Gilmore (1999) batizaram de Economia da Experiência a forma de comercialização na qual o consumidor não adquire simplesmente um produto ou serviço, mas sim paga "para passar algum tempo participando de uma série de eventos memoráveis" (PINE II; GILMORE, 1999, p. 2), demonstrando, assim, que não se compra algo com o intuito de que este exerça simplesmente sua função, mas sim que possibilite satisfazer outros desejos a ele relacionados.

As raízes da experiência de serviços provêm de diferentes disciplinas, incluindo a economia, a psicologia, os estudos de gestão e trabalhos no campo do marketing. Sendo assim, o conhecimento existente nessa temática encontra-se fragmentado e ainda falta uma forma amplamente aceita para integrar essas diferentes perspectivas (KLAUS; MAKLAN, 2012).

O modelo servicescape, proposto por Bitner (1992), mesmo não tendo sido concebido na perspectiva experiencial, foi um dos primeiros trabalhos que, ao definir o conceito de experiência, buscou criar modelos. Para Bitner (1992), as respostas ou reações podem ser divididas em três grupos: respostas cognitivas, respostas emocionais e respostas físicas. O estudo de Pullman e Gross (2003) foca a criação de experiências considerando contextos.

Nesse contexto, pode-se destacar o trabalho de Voss, Roth e Chase (2008), que busca investigar como as empresas criam estratégias de serviços baseados na experiência. Ao criar o termo experience capability (capacidade da experiência), os autores trazem tanto para a literatura de serviços como para as empresas a proposta da operação dos serviços combinarem 
elementos como o stageware (representado pelo layout das instalações, processos e tecnologia), o orgware (que envolve a gestão do sistema de infraestrutura e políticas internas), o customerware (representado pelos pontos de contato do cliente com o sistema de serviços) e, por fim, o linkware (que funciona como a integração de todos os sistemas e processos).

No Brasil também é possível encontrar alguns trabalhos que definiram a questão experiencial dos serviços. Podem ser citados os trabalhos de Carvalho e Motta (2000), Carvalho e Vergara (2002), Carvalho, Lima e Motta (2003), Andrade (2004), Ferreira et al. (2006), Mendonça, Barbosa e Durão (2007), Moura e Lucian (2008), Teixeira e Barbosa (2008) e Aguiar e Farias (2012).

Tradicionalmente, a percepção dos consumidores em relação às suas experiências quanto à qualidade dos serviços tem sido medida pela metodologia proposta por Parasuraman, Zeithaml e Berry (1988): o Servqual. No entanto o Servqual carece de adaptações necessárias à nova realidade empresarial, principalmente a inclusão de tecnologia no dia a dia das estratégias de marketing de serviços.

Objetivando preencher essas lacunas atuais do Servqual e reunir os principais pontos relacionados à mensuração da experiência de consumo, Maklan e Klaus (2011) criaram um construto chamado EXQ (Customer Experience Quality), que contrapõe a tradicional escala Servqual. Primeiramente, a experiência dos serviços deve ser acessada por uma percepção geral do consumidor, não por meio de intervalos entre desempenho e expectativas, e deve ter um valor geral em uso e não apenas uma sumarização do desempenho durante episódios de serviços individuais. Em segundo lugar, a medida de experiência tem um escopo mais amplo do que o proposto pelo Servqual, pois inclui emoções e efeito de pares, começando antes do encontro de serviço e continuando após esse encontro, e deve levar em conta todos os encontros de serviços ao longo do canal de relacionamento. Por fim, segundo os autores, uma medida ideal deveria ligar mais diretamente o comportamento do consumidor e o desempenho do negócio do que o Servqual ou satisfação do consumidor

Assim, baseando-se nesses pontos é que Maklan e Klaus (2011) e Klaus e Maklan $(2012,2013)$ desenvolveram a escala (EXQ) incorporando atributos considerados essenciais na experiência de consumo que não foram devidamente investigados em estudos tradicionais envolvendo qualidade de serviços e satisfação. A partir dessa escala, os autores focaram no impacto das experiências de serviços em variáveis importantes da área de marketing: lealdade, satisfação e boca a boca. Para mensurar as dimensões do construto da experiência em serviço e sua relação com o consumo, os autores chegaram a uma escala composta por quatro dimensões com 19 itens correspondentes: experiência com o produto, foco no resultado, momento da verdade e paz de espírito:

a) experiência com o produto: o consumidor avalia os aspectos funcionais dos serviços ou dos produtos em relação ao acesso que tem a outras ofertas e à sua habilidade de compará-las. Por exemplo, o cliente de uma cooperativa de crédito avalia, nesta dimensão, a qualidade do crédito oferecido a ele em relação à mesma oferta feita por um banco;

b) foco no resultado: o consumidor procura ser o mais eficiente e eficaz com relação à aquisição ao produto ou serviço. Assim, o seu foco é a redução dos custos de transação, tais como buscar e qualificar novos fornecedores. Um cliente de um banco, por exemplo, pode avaliar nesta dimensão as tarifas cobradas pela manutenção da conta corrente; 
c) momentos da verdade: em toda relação de consumo há momentos que precisam adaptar as necessidades e intenções das partes; a literatura chama essas situações de "momentos da verdade". O foco está na importância da recuperação dos serviços e flexibilidade quando o cliente se depara com alguma complicação. A cooperativa pode recuperar a relação com um cliente insatisfeito com alguma situação inadequada pela qual passou em seu relacionamento;

d) paz de espírito: as partes envolvidas nos serviços têm, expressas ou não, uma série de sensações e emoções nas quais o provedor do serviço deve basear suas competências, com base nas competências percebidas do provedor do serviço. 0 cooperado avalia se pode ficar tranquilo com relação a seus investimentos feitos na cooperativa.

Os autores supracitados refinaram seu modelo, propondo um novo modelo teórico a partir dessas quatro dimensões formativas do conceito Experiência em Serviço (experiência com o produto, foco no resultado, momento da verdade e paz de espírito), estabelecendo três dimensões consequentes : lealdade, satisfação e boca a boca.

De acordo com o proposto por Klaus e Maklan (2012, 2013), o EXQ é um melhor preditor da lealdade, da satisfação e do boca a boca do que a qualidade em serviços, o que vem a reforçar a relevância de tal construto, conforme as definições a seguir:

a) lealdade: Prado e Santos (2003) colocam que o estudo das compras repetidas, da lealdade e de seus antecedentes está presente no meio acadêmico há aproximadamente três décadas. Oliver (1997, p. 392) define lealdade como a existência de um comprometimento profundo em comprar ou utilizar novamente um produto ou serviço consistentemente, no futuro, e assim, repetidamente, comprar a mesma marca ou produtos da mesma empresa, apesar de influências situacionais e esforços de marketing para que o consumidor faça outras opções. Uma recompra completamente consistente da mesma marca demonstraria perfeita lealdade comportamental a essa marca, mas, na prática, mesmo consumidores leais podem desviar de sua marca regular comprando ocasionalmente uma marca alternativa. Para incluir a consistência imperfeita mensura-se a lealdade comportamental de vários modos: proporção de compra, sequência de compra e probabilidade de compra (SHETH, MITAL; NEWMAN, 2001);

b) satisfação: Oliver (1997) afirma que satisfação é um caminho indispensável para o desenvolvimento da lealdade, mas que somente satisfação não garante que o consumidor será leal à empresa ou à marca. A satisfação pode ser utilizada para entender melhor as decisões de compra dos clientes, mas não deve ser utilizada como um objetivo em si, como forma de remunerar empregados, independente da lealdade do cliente; esta, sim, intrinsecamente ligada com a entrega de valor superior ao cliente (REICHHELD, MARKEY JR; HOPTON, 2000);

c) boca a boca: constitui um relevante comportamento quando analisamos a experiência em serviços. Conforme argumenta Gremler (1994), o boca a boca é a maior fonte de informações que os clientes utilizam em suas decisões de compra, como ocorre, por exemplo, nos setores de cosméticos, higiene pessoal e perfumaria, em produtos que envolvam risco de grandes perdas e ainda serviços como cabeleireiros, advogados, dentistas, contadores etc. (BOWN; REIGEN, 1987; HARRISON-WALKER, 2001). 


\section{METODOLOGIA DA PESQUISA}

A presente pesquisa configura-se como um estudo de caso de caráter quantitativo de corte transversal por meio da aplicação de Survey e da determinação de relações entre variáveis.

A opção pelo estudo de caso permitiu uma análise ampla e detalhada sobre a percepção do cooperado com a experiência em serviços com uma cooperativa de crédito no Paraná, tendo como vantagem possibilitar uma contribuição para esta área da Administração da cooperativa.

Com o propósito de contemplar de forma plena os anseios do objetivo central da pesquisa, operacionalmente, esta se desdobrou em dois objetivos específicos, cada qual com sua particularidade metodológica operacional, conforme apresentado no Quadro 1 a seguir:

Quadro 1 - Procedimentos metodológicos operacionais por objetivo específico

\begin{tabular}{|c|c|c|c|c|c|}
\hline Objetivo Específico & Coleta & Análise & População & Amostra & $\begin{array}{l}\text { Resultado } \\
\text { Alcançado }\end{array}$ \\
\hline $\begin{array}{l}\text { a. Identificar a } \\
\text { percepção dos } \\
\text { cooperados com a } \\
\text { experiência em serviços } \\
\text { em uma cooperativa de } \\
\text { crédito; }\end{array}$ & $\begin{array}{l}\text { Questionário } \\
\text { aplicação da } \\
\text { escala EXQ }\end{array}$ & $\begin{array}{l}\text { Descritiva } \\
\text { e Causal - } \\
\text { análise via } \\
\text { PLS }\end{array}$ & $\begin{array}{l}\text { Todos os } \\
\text { cooperados } \\
\text { (4.500 } \\
\text { Coop.). }\end{array}$ & $\begin{array}{l}\text { Não } \\
\text { probabilística } \\
\text { (759 Coop.) }\end{array}$ & $\begin{array}{l}\text { Percepção do } \\
\text { cooperado }\end{array}$ \\
\hline $\begin{array}{l}\text { b. Analisar a experiência } \\
\text { em serviços dos } \\
\text { cooperados sob o corte } \\
\text { específico (renda). }\end{array}$ & $\begin{array}{l}\text { Dados } \\
\text { coletados da } \\
\text { aplicação do } \\
\text { questionário. }\end{array}$ & $\begin{array}{l}\text { Diferença } \\
\text { de média } \\
\text { simples }\end{array}$ & $\begin{array}{l}\text { Todos os } \\
\text { cooperados } \\
(4.500 \\
\text { Coop.). }\end{array}$ & $\begin{array}{l}\text { Não } \\
\text { probabilística } \\
\text { (759 Coop.) }\end{array}$ & $\begin{array}{l}\text { Percepção } \\
\text { sob o corte } \\
\text { específico } \\
\text { renda. }\end{array}$ \\
\hline
\end{tabular}

Fonte: Os Autores (2016).

Com relação à amostra e suas características, é possível perceber o retorno consistente na aplicação do modelo EXQ conforme a Figura 1 a seguir.

Figura 1 - Confiabilidade dos construtos

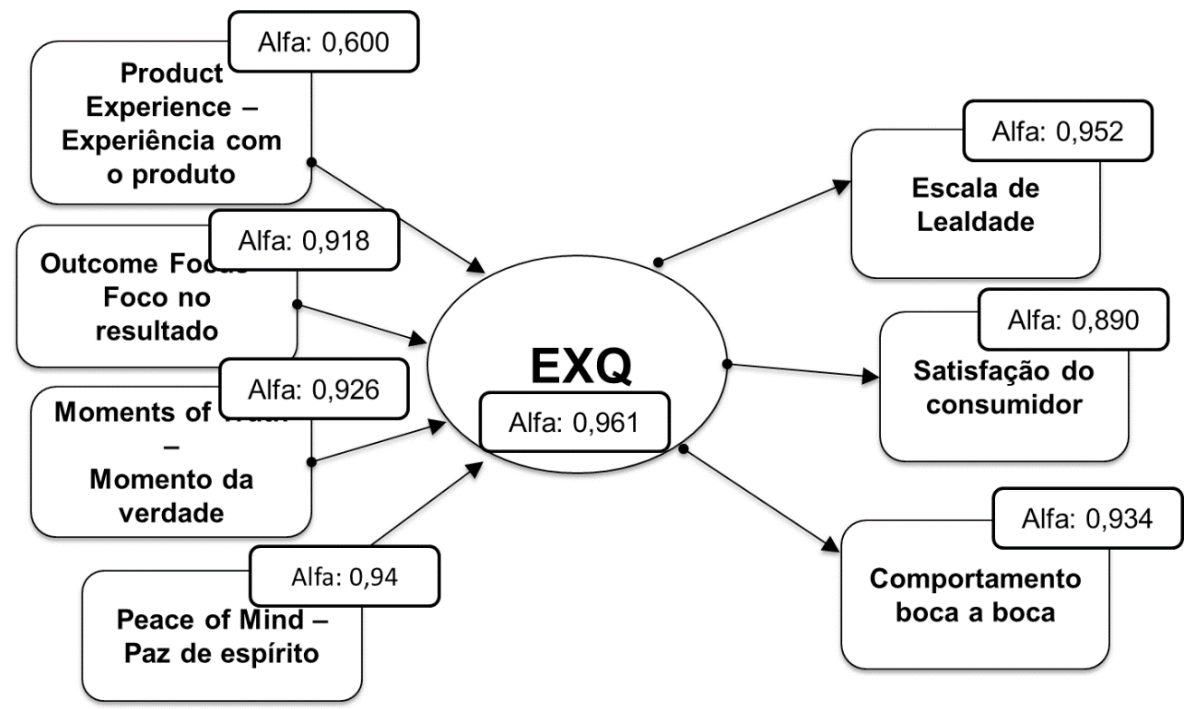

Fonte: Os Autores (2016). 
Considerando que o Alfa de Cronbach, medida para se avaliar a confiabilidade de um fator, vai de 0 a 1, acima de 0,6 é aceitável e, acima de 0,8, é considerado forte, pode-se perceber que, na amostra da pesquisa, o alfa foi aceitável em relação à escala EXQ, lealdade, satisfação e boca a boca.

A percepção dos cooperados em relação à lealdade, satisfação e boca a boca na segmentação de renda foi analisada por meio da realização de três regressões de mínimos quadrados parciais (PLS), cada uma tendo como base uma das três variáveis dependentes: (a) escala de lealdade; (b) satisfação do consumidor; (c) comportamento boca a boca.

A observância do contexto metodológico da pesquisa requereu o posicionamento claro das definições operacionais e constitutivas de cada uma das principais variáveis da pesquisa; para tanto, especial destaque se deu à apresentação das definições das seguintes variáveis:

a) percepção sobre experiência em serviços: para avaliar a percepção do cooperado com relação à experiência em serviços, foi utilizada a escala EXQ, a qual incorpora atributos considerados chave na experiência de consumo envolvendo qualidade de serviços e satisfação. A Escala EXQ é composta por 19 questões referentes ao construto experiência de consumo em suas quatro dimensões (experiência com o produto, foco no resultado, momento da verdade e paz de espírito). Os respondentes explicitaram seu grau de concordância/discordância com as afirmações usando uma escala do tipo Likert de 7 pontos;

b) desempenho em serviços: a percepção dos cooperados foi avaliada por meio de três dimensões : lealdade, satisfação e boca a boca. A escala de lealdade foi composta por cinco questões com base nos trabalhos de Zeithaml, Berry e Parasuraman (1996) e Parasuraman, Zeithaml e Malhotra (2005); a Escala de Satisfação do consumidor tem cinco questões adaptadas das pesquisas de Hubbert, Sehorn e Brown (1995) e Oliver (1997); a Escala Boca a Boca foi composta por sete questões baseada no trabalho de Brown et al. (2005).

\section{APRESENTAÇÃO E ANÁLISE DOS DADOS}

\subsection{Descrição do objeto da pesquisa: a cooperativa}

Desde sua idealização, a Cooperativa estudada está focada em um público específico de atuação. Foi fundada em 3 de janeiro de 1996, por 20 médicos que almejavam atendimento financeiro diferenciado; em setembro do mesmo ano, o Banco Central do Brasil homologou seu funcionamento. Nos anos seguintes, outras cooperativas singulares foram criadas e, em setembro de 1998, foi fundada a sua Central. De 1992 até 2011, a Cooperativa, presente nos estados do Paraná e do Mato Grosso do Sul, estava filiada a um sistema central. Em novembro de 2011, a Central Paraná e Mato Grosso do Sul se desfiliaram desse sistema e criaram um novo sistema, formado por dois níveis, sendo eles: Central (entidade de $2^{\circ}$ grau) e nove cooperativas singulares (entidades de $1^{\circ}$ grau).

Hoje a Cooperativa conta com mais de 5.600 cooperados e atua no segmento de profissionais e estudantes da área de saúde, ascendentes, descendentes e cônjuges de cooperados, bem como as empresas desse ramo da saúde e empresas de qualquer natureza controladas pelos cooperados. 
A Cooperativa tem sua sede em Toledo (PR) e promove experiências por meio de seus serviços em nove postos de atendimentos nos municípios de Toledo, Ubiratã, Goioerê, Medianeira, Marechal Cândido Rondon, Assis Chateaubriand, Palotina, Guaíra e Santa Helena, abrangendo um total de 46 municípios que geograficamente se aproximam dos pontos de atendimento.

\subsection{Análise geral dos dados: experiência em serviço}

A mensuração da experiência em serviços por meio da metodologia proposta suscita a necessidade da estruturação de uma modelagem inicial da aplicação da equação estrutural, com o propósito de mensurar a utilização dos dados para análise da escala EXQ. Na Figura 2, a seguir, é possível observar o contexto geral da modelagem proposta, que compreende a mensuração de 4 fatores distintos.

Os fatores 1 e 2, oriundos das quatro dimensões da escala EXQ, são os geradores do desempenho (Lealdade, Satisfação e Boca a Boca) agrupados nos fatores 3 e 4 . O fator 1 evidencia que os cooperados consideram como relevante para a Experiência em Serviço suas experiências passadas, a variedade dos serviços e a confiança que adquiriram na Cooperativa. Já em relação ao fator 2, a experiência com o produto, evidenciou-se que há uma necessidade do cooperado em comparar os produtos/serviços da Cooperativa com os de outras instituições financeiras e ainda têm a necessidade de obter mais produtos/serviços além dos que a Cooperativa oferece. Ainda, analisando-se os fatores 3 e 4, que resultam dos fatores 1 e 2, evidenciou-se que, apesar da necessidade de mais produtos apresentada no fator 2, o cooperado sente-se bem quando vai à Cooperativa e tem uma impressão positiva desta, e utilizará a Cooperativa nos próximos anos, além de recomendá-la a seus familiares, demonstrando fatores de satisfação e lealdade, conforme observado na Figura 2.

Figura 2 - Modelagem da aplicação da equação estrutural

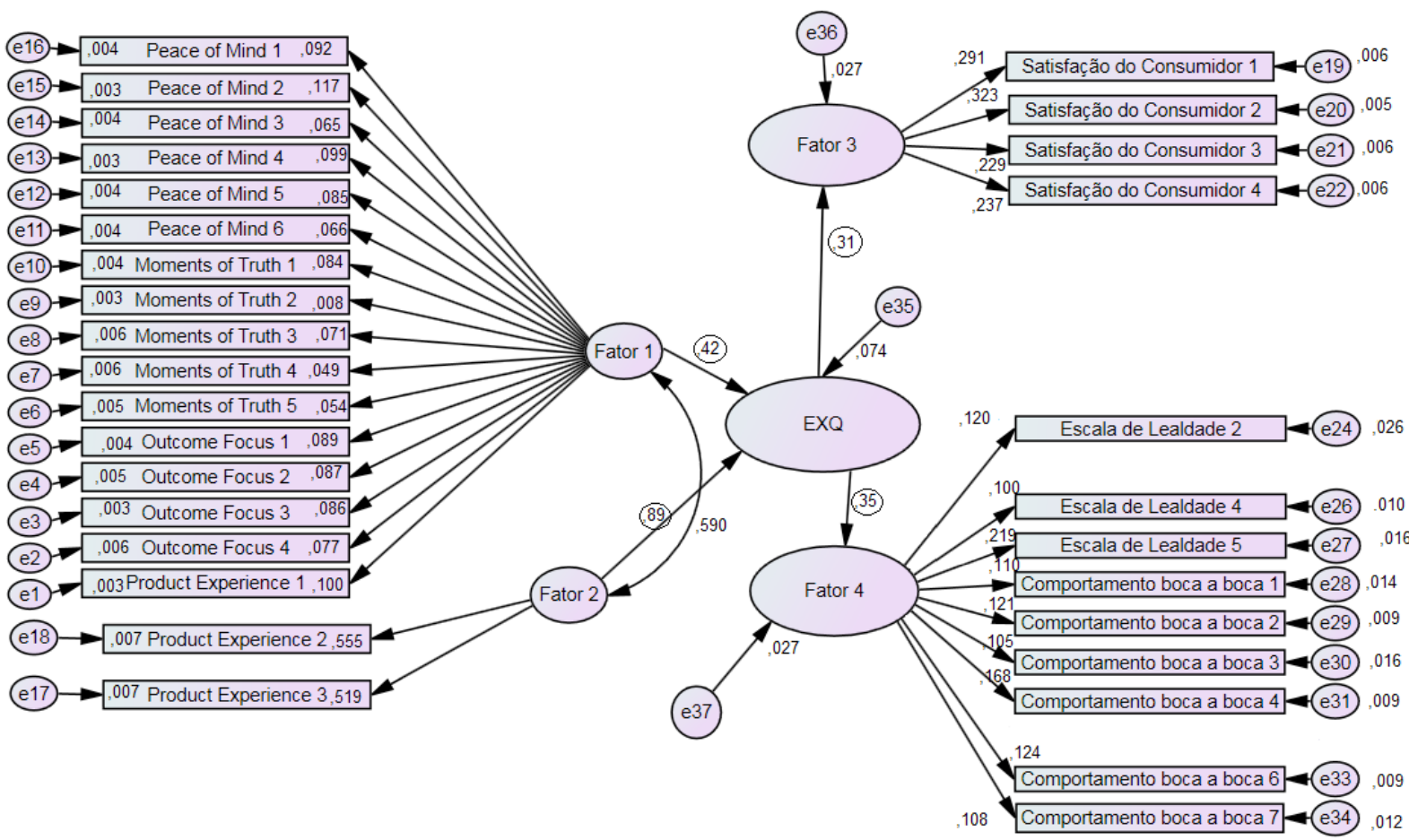

Fonte: Os Autores (2016). 
Diante da necessidade de uma análise mais detalhada dos dados resultantes da experiência em serviços dos cooperados com a Cooperativa, para a tomada de decisões, foram ainda analisados os dados por características subdivididas em Renda, Idade, Gênero, Escolaridade e Cidade. Na presente pesquisa, conforme já mencionado na seção 2, apresentar--se-á, a seguir, a análise da Experiência em Serviços segmentado pela Renda.

\subsection{Experiência em serviços: foco na renda}

O estado do Paraná apresenta-se com o sexto maior rendimento nominal mensal domiciliar per capita da população residente (R\$) do País (IBGE, 2016). Baseado em tal categorização e realidade de renda, a seguir apresenta-se o Quadro 2 com a média geral das respostas a cada pergunta do questionário da pesquisa, inerentes ao enfoque de renda dos cooperados. Com objetivo de facilitar a observação dos dados, em cada linha referente a cada pergunta, encontrase a menor média, com a cor vermelha, e a maior média, com a cor azul. Destacamos ainda na coluna diferença entre maior e menor, na cor verde, as maiores diferenças de médias. Por fim, também destacamos em verde as perguntas PE2 e PE3, que são perguntas invertidas, das quais, quanto maior a nota, pior a análise sob o ponto de vista da escala. 


\begin{tabular}{|c|c|c|c|c|c|c|c|c|c|c|c|c|c|c|c|c|}
\hline & 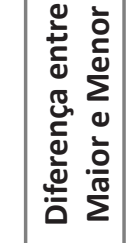 & $\mid \begin{array}{c}\infty \\
m \\
0 \\
0\end{array}$ & $\begin{array}{l}\stackrel{\mu}{n} \\
0 \\
0\end{array}$ & \begin{tabular}{l}
-1 \\
\multirow{\sigma}{*}{} \\
0
\end{tabular} & $\underset{-}{\text { O }}$ & $\begin{array}{l}\tilde{n} \\
\text { 告 }\end{array}$ & 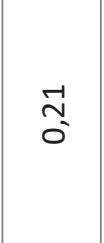 & $\begin{array}{c}\hat{n} \\
0_{0}\end{array}$ & ñ & 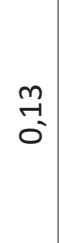 & $\underset{\sigma}{-\vec{t}}$ & $\stackrel{\text { F }}{\circ}$ & 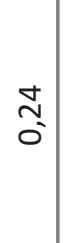 & $\begin{array}{c}\text { શి } \\
\text { o }\end{array}$ & $\begin{array}{l}\stackrel{0}{n} \\
0^{\prime}\end{array}$ & $\begin{array}{l}\text { ㄹ-1 } \\
\text { o. }\end{array}$ \\
\hline & 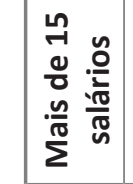 & $\mid \begin{array}{l}-\vec{m} \\
\tilde{0}\end{array}$ & $\begin{array}{l}-1 \\
0 \\
6\end{array}$ & $\begin{array}{l}\text { o } \\
\text { ஸे }\end{array}$ & 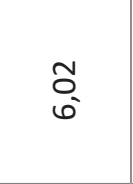 & $\begin{array}{l}0 \\
\stackrel{1}{6} \\
6\end{array}$ & $\stackrel{n_{n}}{\tilde{\omega}^{-}}$ & 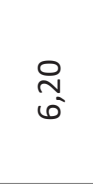 & $\begin{array}{l}0 \\
\stackrel{1}{6} \\
\tilde{\sigma}^{\prime}\end{array}$ & 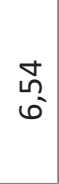 & $\stackrel{9}{9}$ & $\begin{array}{l}-1 \\
0 \\
0\end{array}$ & $\underset{\vec{f}}{\overrightarrow{6}}$ & $\begin{array}{c}\vec{n} \\
\tilde{\omega}^{-}\end{array}$ & ने & 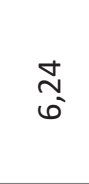 \\
\hline & 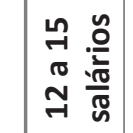 & 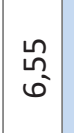 & $\begin{array}{c}\hat{n} \\
\sigma^{-}\end{array}$ & $\begin{array}{l}\hat{A} \\
\text { G }\end{array}$ & 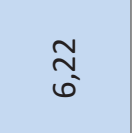 & 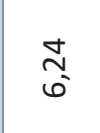 & 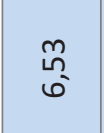 & $\begin{array}{l}-7 \\
\sigma \\
6\end{array}$ & $\begin{array}{l}-1 \\
\tilde{\omega} \\
\sigma^{-}\end{array}$ & 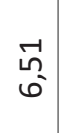 & 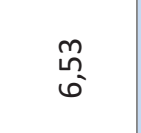 & $\vec{n}_{\tilde{\omega}}^{-1}$ & 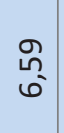 & \begin{tabular}{l}
$f$ \\
\multirow{6}{*}{}
\end{tabular} & 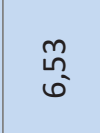 & 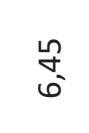 \\
\hline & 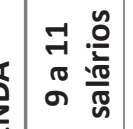 & 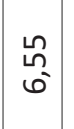 & $\begin{array}{l}8 \\
0 \\
0\end{array}$ & $\mid \begin{array}{l}0 \\
0 \\
0^{-}\end{array}$ & $\begin{array}{l}\text { बे } \\
\text { ஸे }\end{array}$ & 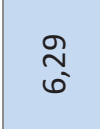 & $\stackrel{\infty}{\sigma^{\circ}}$ & 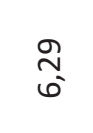 & $\begin{array}{l}0 \\
\sigma^{\prime}\end{array}$ & $\hat{\Theta}_{0}^{n}$ & $\underset{\sigma^{-}}{\stackrel{N}{*}}$ & $\stackrel{\mathscr{N}}{\overbrace{}^{\prime}}$ & \begin{tabular}{l}
$q$ \\
\multirow{6}{*}{}
\end{tabular} & $\begin{array}{l}\stackrel{\infty}{m} \\
\tilde{\omega}^{-}\end{array}$ & $\stackrel{m}{q}^{-}$ & $\begin{array}{l}\stackrel{\circ}{\circ} \\
\mathscr{b}^{-}\end{array}$ \\
\hline & 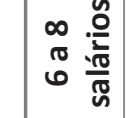 & 孚 & 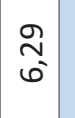 & $\begin{array}{l}-1 \\
6 \\
6\end{array}$ & $\begin{array}{l}\infty \\
\infty \\
\text { ñ }\end{array}$ & $\stackrel{m}{\underset{6}{6}}$ & $\stackrel{q}{q}^{q}$ & $\vec{n}_{\tilde{\omega}}^{-1}$ & $\begin{array}{l}\stackrel{\infty}{-1} \\
\stackrel{-1}{6}\end{array}$ & $\begin{array}{l}\infty \\
\stackrel{n}{n} \\
\emptyset\end{array}$ & 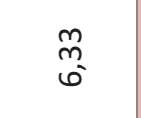 & $\begin{array}{l}\infty \\
\infty \\
n^{\infty}\end{array}$ & 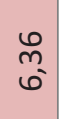 & 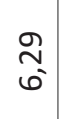 & 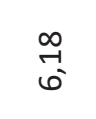 & $\begin{array}{l}\stackrel{2}{2} \\
\stackrel{1}{6}\end{array}$ \\
\hline & 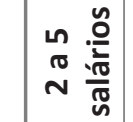 & 売 & $\stackrel{\vec{\jmath}}{\sigma}$ & 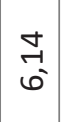 & $\begin{array}{l}\text { ถึ } \\
\text { ஸึ }\end{array}$ & 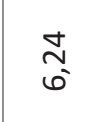 & 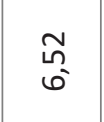 & $\begin{array}{l}-1 \\
\tilde{\sigma}^{-}\end{array}$ & $\begin{array}{l}\stackrel{0}{N} \\
\sigma^{\prime}\end{array}$ & 芯 & 吝 & $\underset{\sigma^{-}}{\stackrel{d}{-}}$ & $\begin{array}{l}\stackrel{2}{q} \\
6\end{array}$ & $\begin{array}{l}-\vec{n} \\
\tilde{\sigma}^{\prime}\end{array}$ & $\stackrel{\infty}{\sim}^{\sim}$ & $\mathfrak{n}_{\sigma^{\prime}}$ \\
\hline & 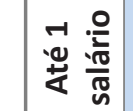 & $\begin{array}{l}0 \\
6 \\
6\end{array}$ & $\begin{array}{l}-1 \\
0 \\
n^{-}\end{array}$ & 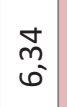 & 定 & $\frac{\infty}{\stackrel{\infty}{n^{-}}}$ & $\begin{array}{l}\text { 员 } \\
\text { ". }\end{array}$ & $\begin{array}{l}8 \\
0 \\
0\end{array}$ & 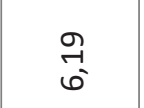 & \begin{tabular}{l}
8 \\
\multirow{6}{*}{}
\end{tabular} & $\stackrel{7}{\vec{f}}$ & $\underbrace{\mathbb{Z}}_{G}$ & $\begin{array}{l}\overrightarrow{7} \\
6 \\
6\end{array}$ & $\begin{array}{l}\overrightarrow{7} \\
\overrightarrow{6}\end{array}$ & $\begin{array}{l}\stackrel{\infty}{m} \\
\sigma^{-}\end{array}$ & $\begin{array}{l}8 \\
\text { o. } \\
6\end{array}$ \\
\hline & 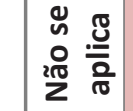 & 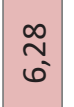 & $\begin{array}{c}0 \\
\stackrel{-}{6} \\
6\end{array}$ & $\begin{array}{c}0 \\
0 \\
0\end{array}$ & $\begin{array}{l}\stackrel{\omega}{m} \\
\text { மn }\end{array}$ & $\begin{array}{l}\text { Ln } \\
\infty \\
\text { ஸ゙ }\end{array}$ & $\begin{array}{c}\tilde{N} \\
\tilde{c}^{-}\end{array}$ & $\begin{array}{l}8 \\
0 \\
0^{-}\end{array}$ & $\begin{array}{l}\text { o } \\
\text { in }\end{array}$ & $\begin{array}{l}\text { 员 } \\
\text { ○' }\end{array}$ & $\stackrel{n}{n}_{\tilde{\sigma}}^{-}$ & $\stackrel{\infty}{\stackrel{\infty}{n}}$ & $\begin{array}{l}\overrightarrow{7} \\
6 \\
6\end{array}$ & \begin{tabular}{l}
$\infty$ \\
\multirow{6}{*}{} \\
$\hat{\sigma}^{\prime}$
\end{tabular} & 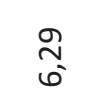 & 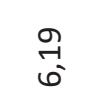 \\
\hline & 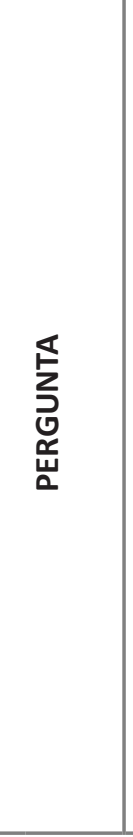 & 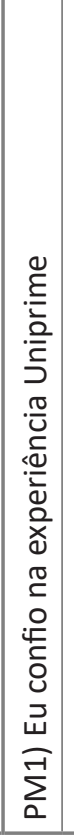 & 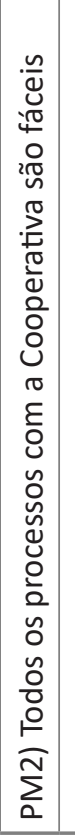 & 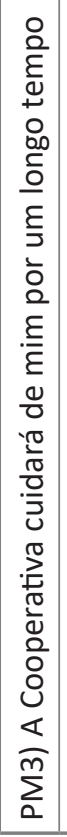 & 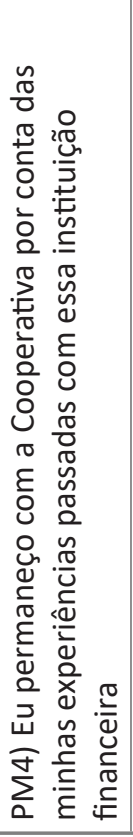 & 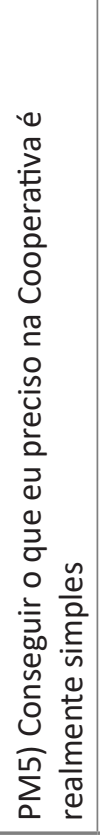 & 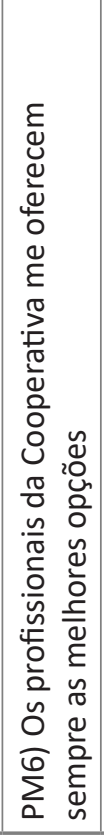 & 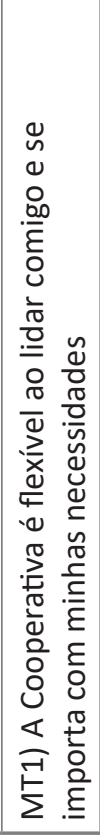 & 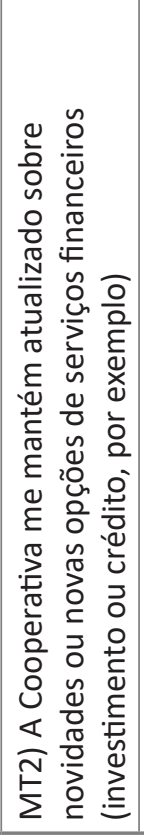 & 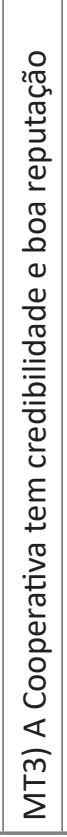 & 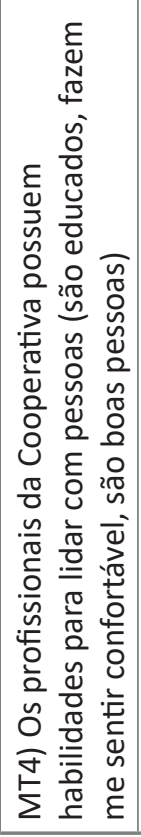 & 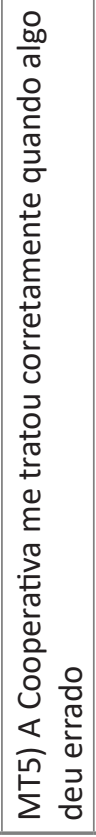 & 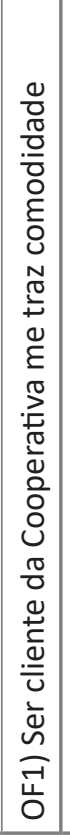 & 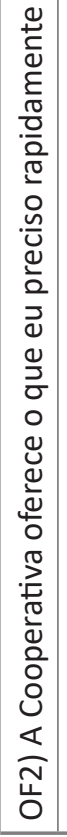 & 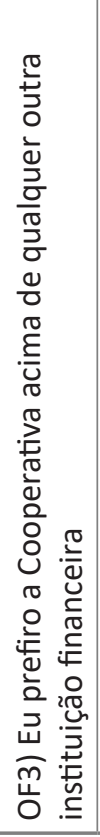 & 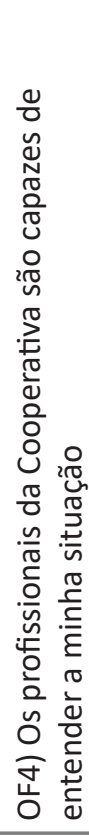 \\
\hline
\end{tabular}




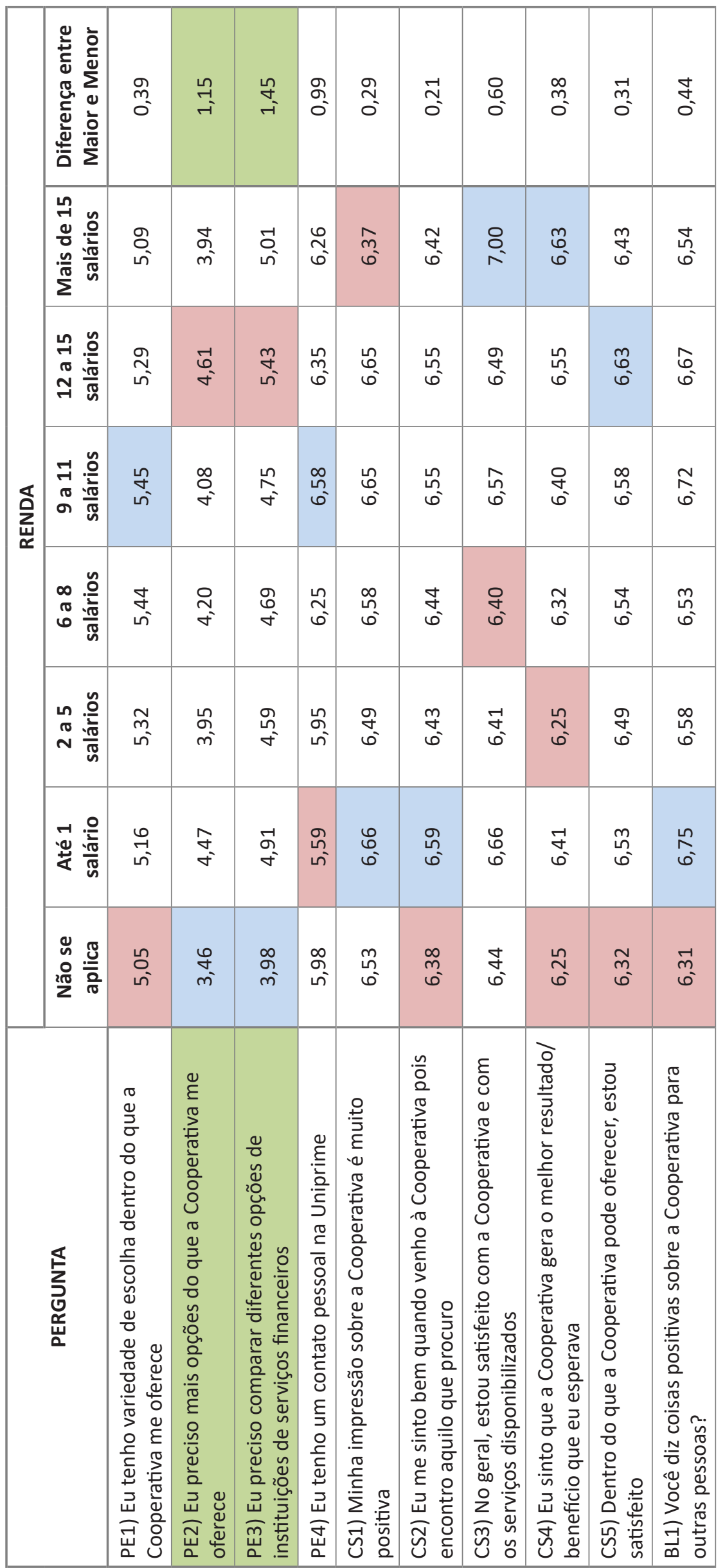




\begin{tabular}{|c|c|c|c|c|c|c|c|c|c|c|c|c|}
\hline & 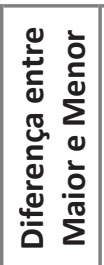 & 占 & $\begin{array}{l}\overrightarrow{6} \\
0\end{array}$ & $\begin{array}{l}\mathbb{N} \\
\tilde{0}\end{array}$ & กิ & $\begin{array}{l}\text { ณ̂ } \\
\text { ó }\end{array}$ & $\frac{\infty}{0^{\prime}}$ & \begin{tabular}{l}
\multirow{G}{0}{} \\
$0^{-}$
\end{tabular} & $\begin{array}{l}\text { L̊ } \\
\text { ó }\end{array}$ & $\begin{array}{l}6 \\
0 \\
0\end{array}$ & $\begin{array}{l}\frac{m}{\tilde{0}} \\
-\end{array}$ & $\begin{array}{l}\overrightarrow{1} \\
0 \\
0\end{array}$ \\
\hline & 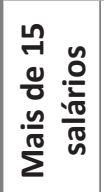 & $\hat{n}_{\emptyset}^{\hat{n}}$ & ָৃ) & $\underset{0}{8}$ & 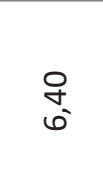 & $\begin{array}{l}\text { ने } \\
\text { ' }\end{array}$ & $\begin{array}{l}\overrightarrow{0} \\
\text { ஸn }\end{array}$ & 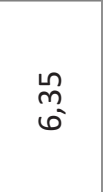 & न् & $\stackrel{m}{\overbrace{6}^{\prime}}$ & 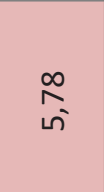 & $\begin{array}{l}\mathscr{\leftrightarrow} \\
\text { ஸे }\end{array}$ \\
\hline & 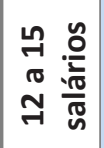 & o̊ & $\stackrel{\mathscr{m}}{f}$ & $\underset{7}{-1}$ & $\stackrel{\Re}{\bigcap}^{n}$ & o̊ & ఝึ & $\begin{array}{l}\vec{b} \\
6\end{array}$ & 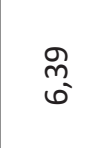 & $\begin{array}{l}\vec{b} \\
6\end{array}$ & 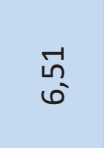 & 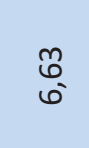 \\
\hline 息 & 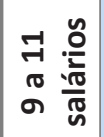 & o̊ & 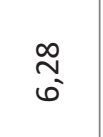 & 妾 & $\stackrel{Q}{Q}_{0}^{\circ}$ & $\stackrel{\infty}{f}$ & 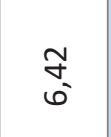 & ర్ & $\underset{\overbrace{}}{\stackrel{\overbrace{}}{\sigma}}$ & ڤึ & $\frac{8}{0}$ & 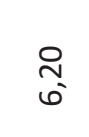 \\
\hline & 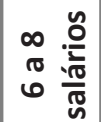 & గ్ ్ֶ & $\stackrel{\text { ֻ }}{\sigma}$ & 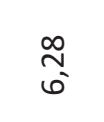 & $\stackrel{\infty}{+}$ & 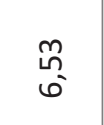 & $\underset{6}{\stackrel{7}{6}}$ & $\begin{array}{l}-1 \\
\text { ñ } \\
\sigma^{\prime}\end{array}$ & 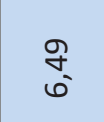 & $\begin{array}{l}0 \\
\text { ñ } \\
\sigma^{\prime}\end{array}$ & 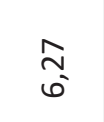 & $\underset{0}{\stackrel{-}{+}}$ \\
\hline & 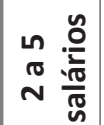 & $\begin{array}{l}\text { 梵 } \\
\text { ' }\end{array}$ & $\stackrel{\infty}{m}_{\omega^{\prime}}$ & 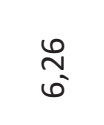 & $\begin{array}{c}\stackrel{9}{m} \\
\text { }\end{array}$ & 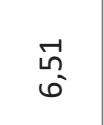 & 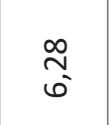 & $\stackrel{\infty}{+}$ & 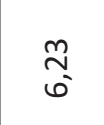 & 每 & $\begin{array}{l}0 \\
\stackrel{-1}{6}\end{array}$ & 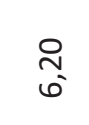 \\
\hline & 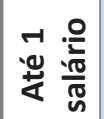 & $\begin{array}{l}\text { ఠ్ } \\
\text { '- }\end{array}$ & $\begin{array}{l}0 \\
\text { ஸ⿱ } \\
\text { ' }\end{array}$ & $\begin{array}{l}\frac{N}{6} \\
6\end{array}$ & $\stackrel{n}{n}^{n}$ & $\begin{array}{l}\vec{n} \\
\sigma^{-}\end{array}$ & $\stackrel{m}{\stackrel{m}{6}}$ & $\underset{G}{\stackrel{J}{*}}$ & $\begin{array}{l}8 \\
0 \\
6\end{array}$ & $\begin{array}{l}\text { જे } \\
\text { ஸे }\end{array}$ & $\stackrel{\infty}{m}_{\underbrace{\infty}}$ & $\begin{array}{l}\vec{m} \\
\emptyset^{-}\end{array}$ \\
\hline & 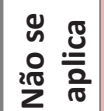 & $\stackrel{m}{\stackrel{m}{6}}$ - $^{-}$ & $\begin{array}{l}\text { ஸू } \\
\text { ஸे }\end{array}$ & $\begin{array}{l}8 \\
0 \\
6\end{array}$ & $\begin{array}{l}\infty \\
0 \\
0\end{array}$ & $\stackrel{ન}{ન}$ & $\begin{array}{l}\text { @ } \\
\text { in }\end{array}$ & $\begin{array}{l}\text { ڤ } \\
\text { ஸे }\end{array}$ & $\begin{array}{l}\text { Oे } \\
\text { in }\end{array}$ & $\begin{array}{l}\infty \\
0 \\
0\end{array}$ & $\begin{array}{l}\infty \\
\infty \\
\text { n' }\end{array}$ & $\begin{array}{l}\text { on } \\
\text { in }\end{array}$ \\
\hline & 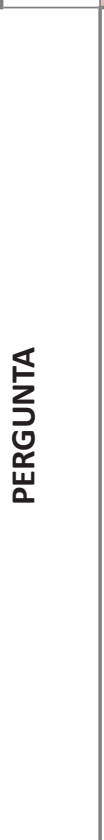 & 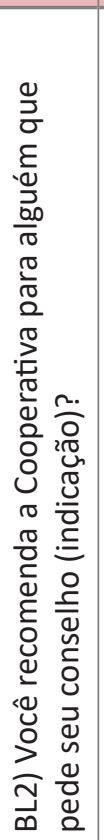 & 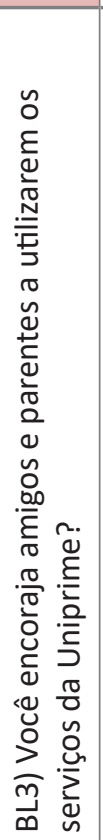 & 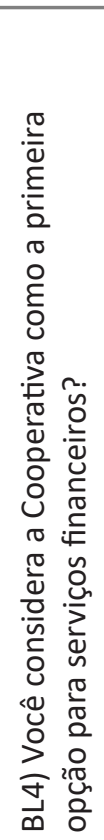 & 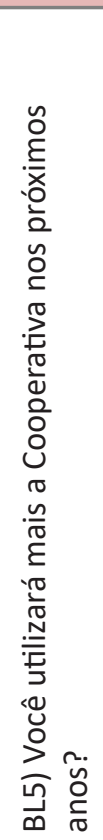 & 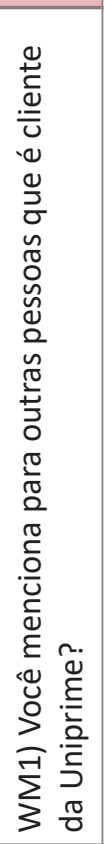 & 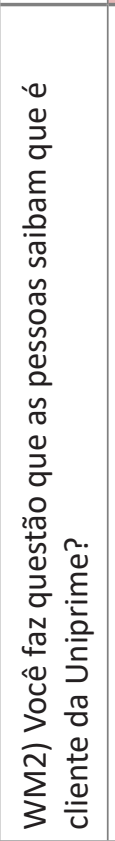 & 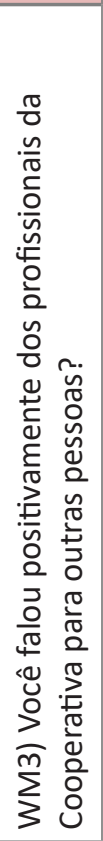 & 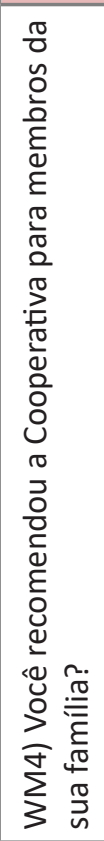 & 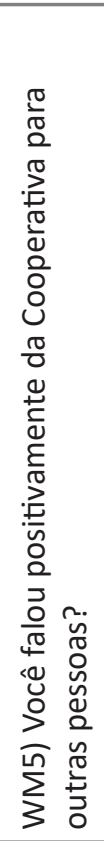 & 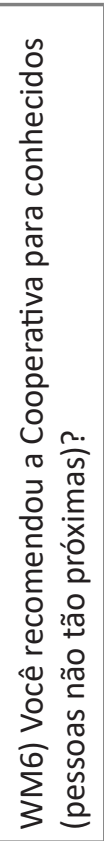 & 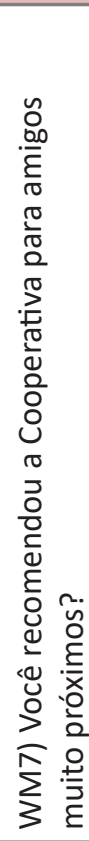 \\
\hline
\end{tabular}


Do Quadro 2, pode-se evidenciar que o maior volume de pontos, quando considerada a diferença entre a maior e a menor média é a da pergunta PE3- "Eu preciso comparar diferentes opções de instituições de serviços financeiros", obtendo um valor de 1,45 pontos; a segunda maior diferença de média observada foi a da pergunta PE2 - "Eu preciso mais opções do que a Cooperativa me oferece", com um valor de 1,15 pontos.

Com relação à distribuição da amostra, 759 respondentes, 13,97\% preferiram não declarar sua renda, 3,95\% declararam uma renda de até um salário mínimo, 45,72\% declararam uma renda de 2 a 5 salários mínimos, 12,78\%, uma renda de 6 a 8 salários mínimos, 6,59\% da amostra declararam uma renda de 9 a 11 salários, 3,95\%, uma renda de 12 a 15 salários, e 13,04\% declararam possuir uma renda superior a 15 salários. Nesse contexto, pode-se perceber que as menores notas se concentram na classe que não respondeu a renda (coluna não se aplica) e na classe com renda até 1 salário. Percebe-se ainda que as concentrações das maiores notas se encontram nas faixas de renda de 9 a 11 salários e na faixa de 12 a 15 salários, o que pode denotar um foco mais específico da organização cooperativa junto a cooperados com as características inerentes a essa faixa de renda, confirmando o ideal de sua fundação.

\subsubsection{Aplicação da Modelagem: faixa de renda}

O modelo teórico da pesquisa demostra a seguir (Figura 3) as variáveis Experiência com Produto, Foco no Resultado, Momento da Verdade e Paz de Espírito, como variáveis independentes e, em seguida, as variáveis Lealdade, Satisfação e Boca a Boca como variáveis dependentes.

Para cada faixa de renda, os dados foram rodados separadamente. Foram realizadas três regressões de mínimos quadrados parciais (PLS), cada uma tendo como base uma das três variáveis dependentes: (a) Escala de Lealdade; (b) Satisfação do Consumidor; (c) Comportamento Boca a Boca. As regressões foram realizadas pelo método stepwise, no qual as variáveis não significativas são retiradas do modelo.

Para analisar cada uma das variáveis dependentes, foi tomada a média de cada uma delas. Tal fato se justifica pelo Alfa de Cronbach alto de cada variável. Foram identificadas as questões que eram significativas no modelo e que mais influenciaram a variável dependente.

Figura 3 - Modelo teórico por faixa de renda

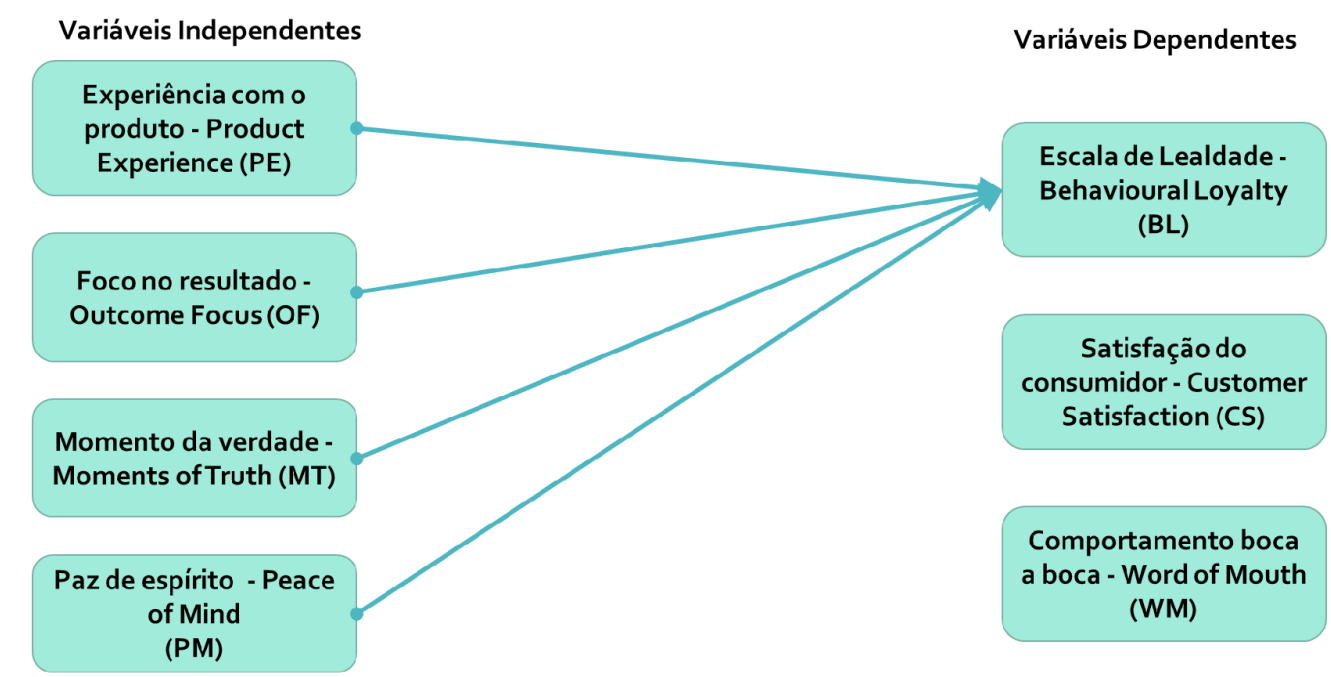

Fonte: Os Autores (2016). 
Abaixo, na Figura 4, são apresentadas a confiabilidade dos construtos e a variância total por eles explicada. A confiabilidade do construto foi verificada por meio do Alpha de Cronbach. Essa análise de confiabilidade produz resultados que variam de 0 a 1 , no qual os valores menores ou iguais a 0,60 indicam, em geral, confiabilidade insatisfatória da consistência, valores acima de 0,6 são considerados aceitáveis e, acima de 0,8 , são considerados fortes. Já a variância explicada faz referência ao coeficiente de determinação (R2), que é uma medida de ajuste de um modelo estatístico que mostra o quanto ele consegue explicar os valores observados na amostra.

Figura 4 - Confiabilidade dos construtos
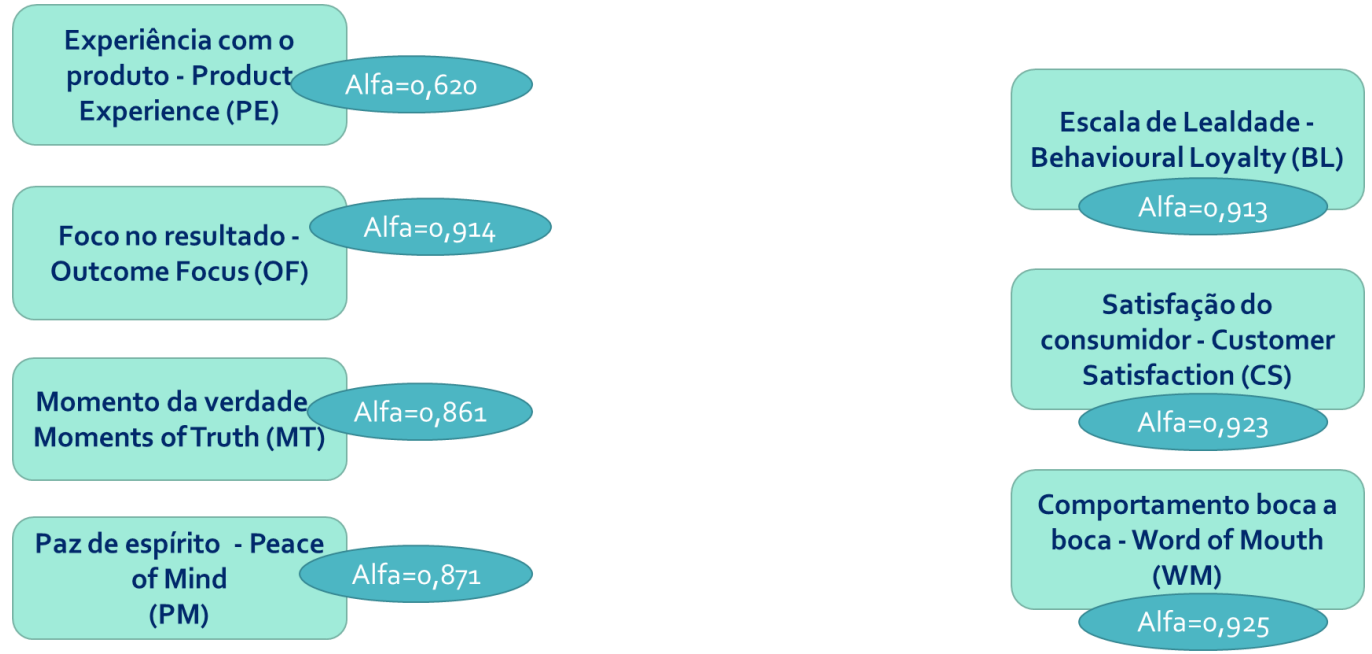

Fonte: Os Autores (2016).

A seguir, apresenta-se o Quadro 3, que corresponde às questões identificadas que se apresentam significativas no modelo, por faixa de renda e que mais influenciaram a variável dependente. 


\begin{tabular}{|c|c|c|c|}
\hline og & 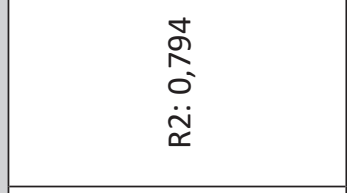 & 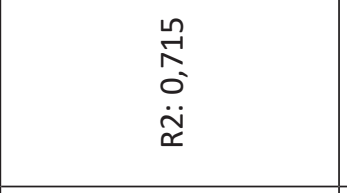 & $\begin{array}{l}\mathscr{0} \\
\infty \\
0 \\
\ddot{\sim} \\
\ddot{\sim}\end{array}$ \\
\hline $\mid \begin{array}{l}\frac{\pi}{\pi} \\
\pi \\
\infty \\
\pi \\
0 \\
\check{\alpha}\end{array}$ & 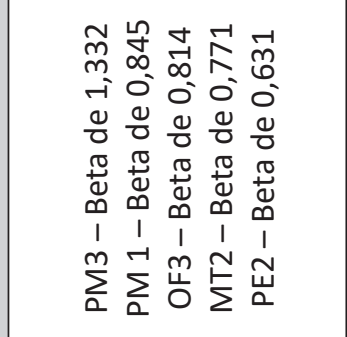 & 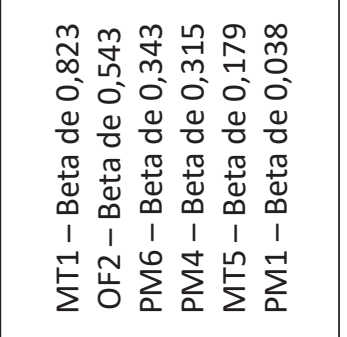 & 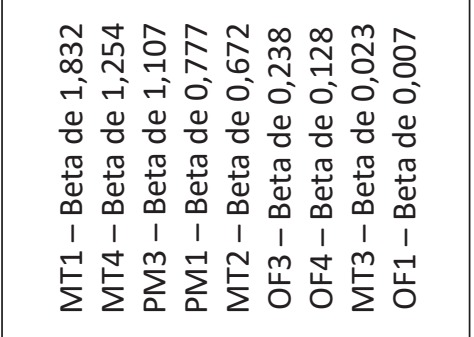 \\
\hline б & $\begin{array}{l}\tilde{I} \\
\infty \\
0 \\
\ddot{\ddot{x}} \\
\ddot{x}\end{array}$ & 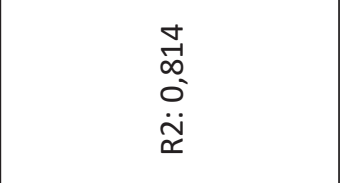 & $\begin{array}{l}0 \\
\stackrel{1}{0} \\
0 \\
\ddot{\Upsilon}\end{array}$ \\
\hline 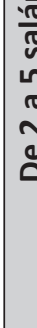 & 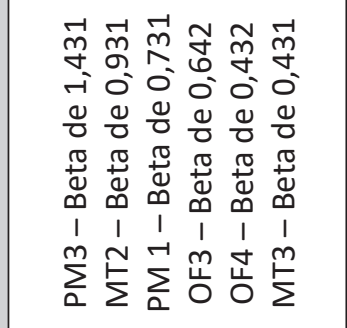 & 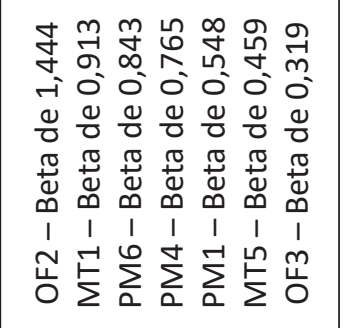 & 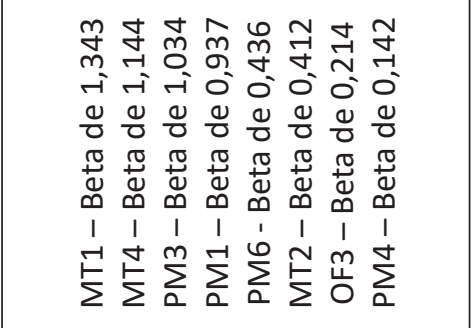 \\
\hline & $\begin{array}{l}\hat{\Omega} \\
\hat{\circ} \\
\ddot{\check{x}}\end{array}$ & $\begin{array}{l}\text { ㄱ. } \\
\hat{0} \\
\ddot{\sim} \\
\tilde{\sim}\end{array}$ & 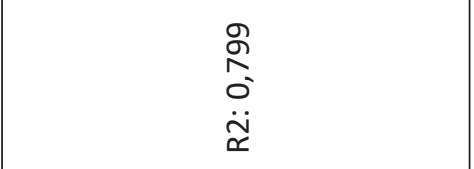 \\
\hline$\frac{\sqrt{2}}{\frac{d}{2}}$ & 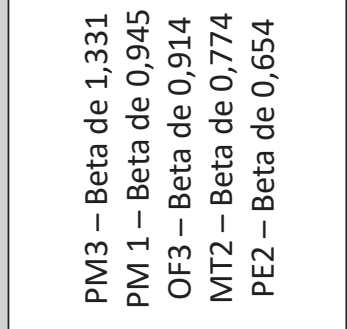 & 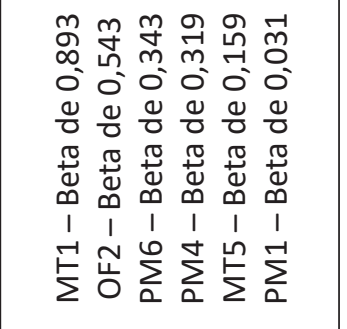 & 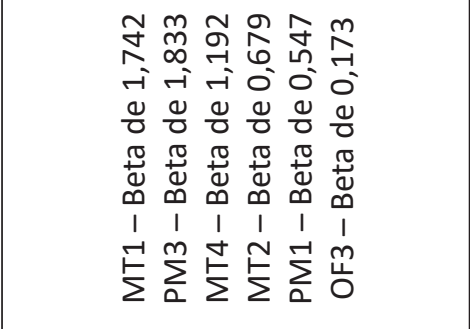 \\
\hline 7 & 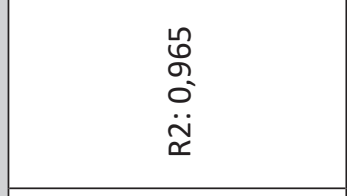 & $\begin{array}{l}\text { J } \\
\hat{0} \\
\ddot{\sim} \\
\ddot{\simeq}\end{array}$ & $\begin{array}{l}\infty \\
\hat{\sigma} \\
\sigma \\
\check{\tilde{x}} \\
\ddot{\tilde{x}}\end{array}$ \\
\hline & 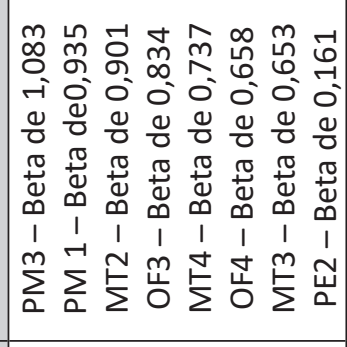 & 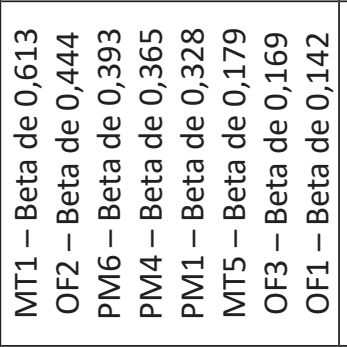 & 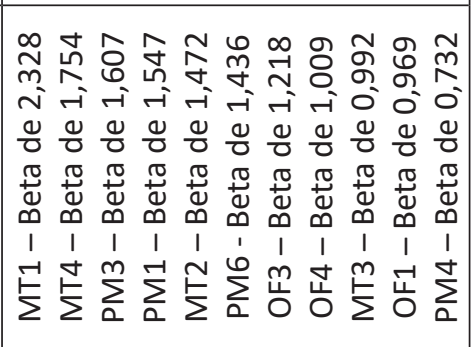 \\
\hline & 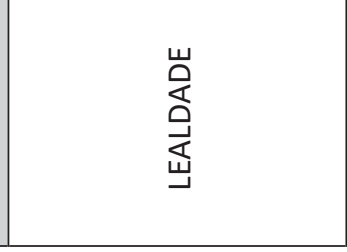 & 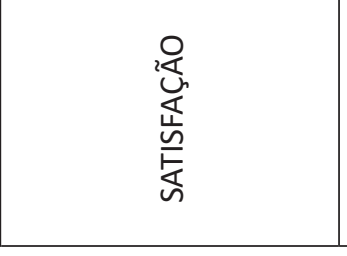 & 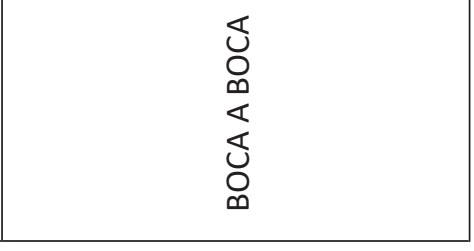 \\
\hline
\end{tabular}




\begin{tabular}{|c|c|c|c|}
\hline \multirow{2}{*}{ 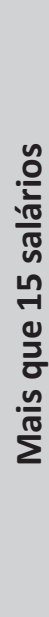 } & $\begin{array}{l}\infty \\
\infty \\
\infty \\
0 \\
\ddot{\ddot{~}} \\
\check{x}\end{array}$ & $\begin{array}{l}\infty \\
\infty \\
\infty \\
0 \\
\ddot{\check{x}} \\
\ddot{\check{x}}\end{array}$ & $\begin{array}{l}\infty \\
\infty \\
\infty \\
0 \\
\ddot{\sim} \\
\ddot{x}\end{array}$ \\
\hline & 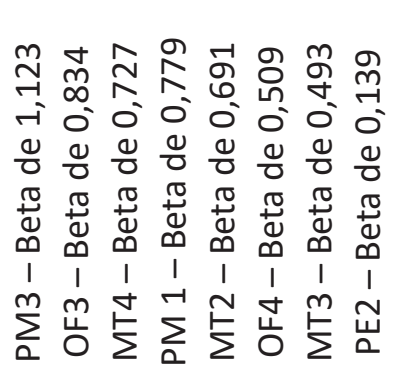 & 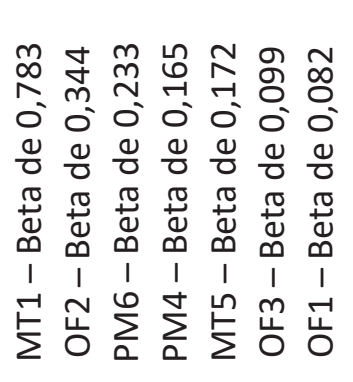 & 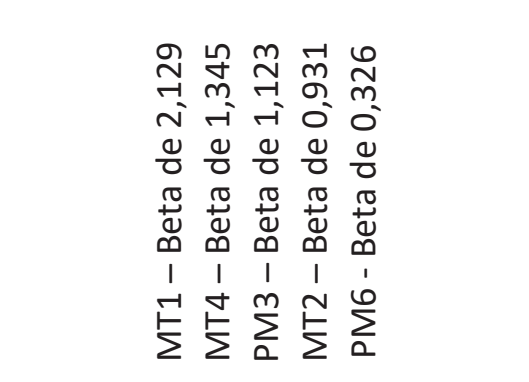 \\
\hline \multirow{2}{*}{ 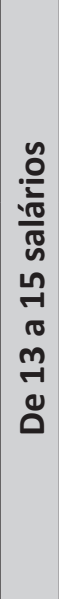 } & 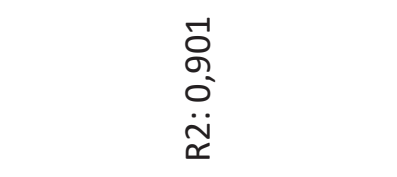 & $\begin{array}{l}\tilde{\sigma} \\
\delta \\
o \\
\ddot{\sim} \\
\ddot{\sim}\end{array}$ & $\begin{array}{l}\mathscr{1} \\
\infty \\
\infty \\
0 \\
\ddot{\sim} \\
\check{x}\end{array}$ \\
\hline & 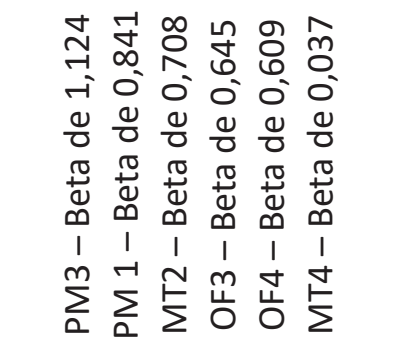 & 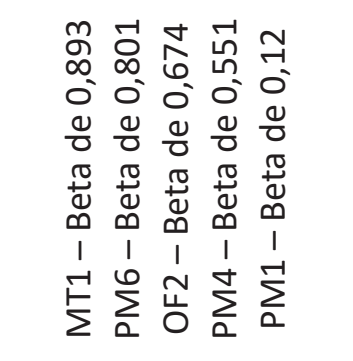 & 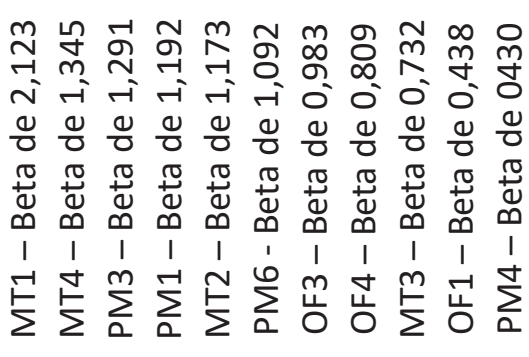 \\
\hline \multirow{2}{*}{ 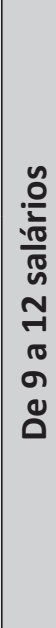 } & $\begin{array}{l}\text { ते } \\
\infty \\
0 \\
\ddot{\check{x}} \\
\ddot{x}\end{array}$ & 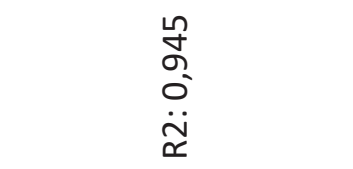 & $\begin{array}{l}\mathscr{0} \\
\dddot{\infty} \\
\infty \\
\check{0} \\
\ddot{\sim}\end{array}$ \\
\hline & 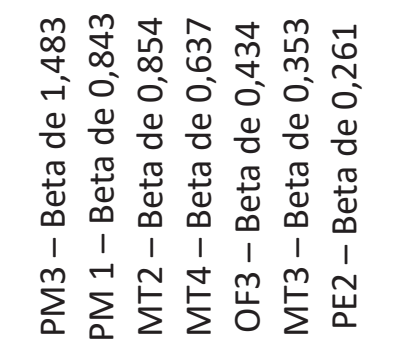 & 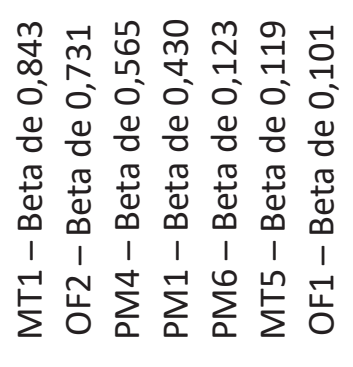 & 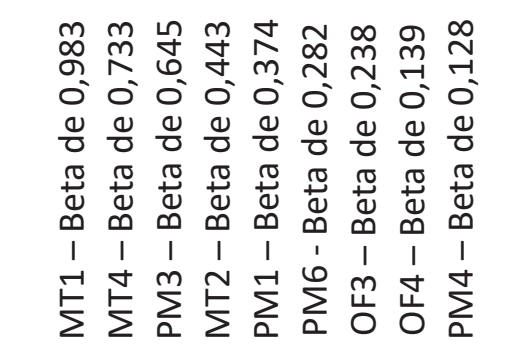 \\
\hline 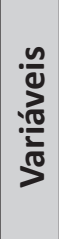 & $\begin{array}{l}\text { 㟯 } \\
\text { 峞 } \\
\text { 岁 }\end{array}$ & 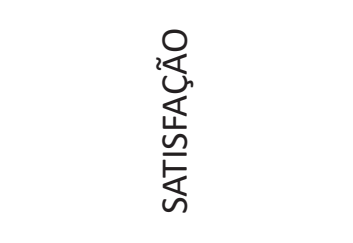 & 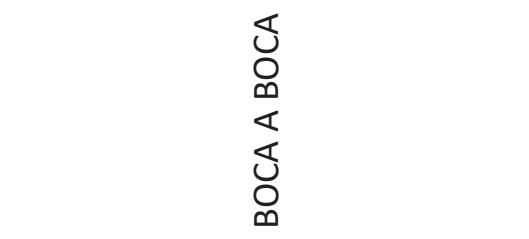 \\
\hline
\end{tabular}


Ao analisar o Quadro 3, com os itens resultantes de Lealdade, Satisfação e Boca a Boca, foi possível identificar as faixas que possuem maior relevância; destacam-se abaixo alguns pontos que devem ser considerados.

Observou-se que o maior número de respondentes encontra-se na faixa de 2 a 5 salários de renda; sendo possível ainda evidenciar as perguntas que se destacam nas três variáveis: (a) MT1) A Cooperativa é flexível ao lidar comigo e se importa com minhas necessidades; (b) MT2) A Cooperativa me mantém atualizado sobre novidades ou novas opções de serviços financeiros (investimento ou crédito, por exemplo); (c) MT3) A Cooperativa tem credibilidade e boa reputação; (d) MT4) Os profissionais da Cooperativa possuem habilidades para lidar com pessoas (são educados, fazem me sentir confortável, são boas pessoas); (e) MT5) A Cooperativa me tratou corretamente quando algo deu errado; (f) OF1) Ser cliente da Cooperativa me traz comodidade; (g) OF2) A Cooperativa oferece o que eu preciso rapidamente; (h) OF3) Eu prefiro a Cooperativa acima de qualquer outra instituição financeira; (i) OF4) Os profissionais da Cooperativa são_capazes de entender a minha situação; (j) PM1) Eu confio na experiência Uniprime; (k) PM3) A Cooperativa cuidará de mim por um longo tempo; (I) PM4) Eu permaneço com a Cooperativa por conta das minhas experiências passadas com essa instituição financeira; (m) PM6) Os profissionais da Cooperativa me oferecem sempre as melhores opções.

Percebe-se ainda que a faixa de renda que obteve a maior incidência de maiores médias foram as faixas com renda de 9 a 11 salários e de 13 a 15 salários. As perguntas que apresentaram maior Beta nas variáveis Lealdade, Satisfação e Boca a Boca nessas duas faixas de renda foram: (a) MT1) A Cooperativa é flexível ao lidar comigo e se importa com minhas necessidades; (b) MT2) A Cooperativa me mantém atualizado sobre novidades ou novas opções de serviços financeiros (investimento ou crédito, por exemplo); (c) MT3) A Cooperativa tem credibilidade e boa reputação; (d) MT4) Os profissionais da Cooperativa possuem habilidades para lidar com pessoas (são educados, fazem me sentir confortável, são boas pessoas); (e) MT5) A Cooperativa me tratou corretamente quando algo deu errado; (f) OF1) Ser cliente da Cooperativa me traz comodidade; (g) OF2) A Cooperativa oferece o que eu preciso rapidamente; (h) OF3) Eu prefiro a Cooperativa acima de qualquer outra instituição financeira; (i) OF4) Os profissionais da Cooperativa são capazes de entender a minha situação; (j) PE2) Eu preciso mais opções do que a Cooperativa me oferece; (k) PM1) Eu confio na experiência Uniprime; (I) M3) A Cooperativa cuidará de mim por um longo tempo; (m) PM4) Eu permaneço com a Cooperativa por conta das minhas experiências passadas com essa instituição financeira; (n) PM6) Os profissionais da Cooperativa me oferecem sempre as melhores opções.

Pode-se observar que nas faixas de renda de 9 a 11 salários e de 12 a 15 salários foram acrescentadas duas novas perguntas cujas respostas tiveram um peso significativo em relação à anterior, sendo elas: (a) OF1) Ser cliente da Cooperativa me traz comodidade; (b) PE2) Eu preciso mais opções do que a Cooperativa me oferece.

Por fim, em relação à Renda, complementa-se a análise por meio da Tabela 1, a qual apresenta a média dos resultados das variáveis dependentes. Destacados em verde estão as médias mais altas em cada uma das escalas e, em vermelho, as médias mais baixas. 
Tabela 1 - Média dos resultados das variáveis dependentes por renda

\begin{tabular}{l|c|cc|cc|cc}
\hline \multirow{2}{*}{$\begin{array}{l}\text { Renda - Salários } \\
\text { mínimos }\end{array}$} & \multirow{2}{*}{$\begin{array}{c}\text { Número } \\
\text { de Casos }\end{array}$} & \multicolumn{2}{|c|}{ Escala de Lealdade } & \multicolumn{2}{c|}{$\begin{array}{c}\text { Satisfação do } \\
\text { Consumidor }\end{array}$} & \multicolumn{2}{c}{$\begin{array}{c}\text { Comportamento } \\
\text { Boca a Boca }\end{array}$} \\
\cline { 3 - 9 } & & $\begin{array}{c}\text { Média } \\
\text { (Max 7) }\end{array}$ & $\begin{array}{c}\text { Desvio } \\
\text { Padrão }\end{array}$ & $\begin{array}{c}\text { Média } \\
\text { (Max 7) }\end{array}$ & $\begin{array}{c}\text { Desvio } \\
\text { Padrão }\end{array}$ & $\begin{array}{c}\text { Média } \\
\text { (Max 7) }\end{array}$ & $\begin{array}{c}\text { Desvio } \\
\text { Padrão }\end{array}$ \\
\hline $\begin{array}{l}\text { Até 1 salário } \\
\text { mínimo }\end{array}$ & 30 & 6,554 & 0,378 & $\underline{6,664}$ & 0,665 & 6,610 & 0,874 \\
\hline $\begin{array}{l}2 \text { a } 5 \text { salários } \\
\text { mínimos }\end{array}$ & 347 & $\underline{6,662}$ & 0,535 & 6,651 & 0,723 & $\underline{6,673}$ & 0,784 \\
\hline $\begin{array}{l}6 \text { a 8 salários } \\
\text { mínimos }\end{array}$ & 97 & 6,564 & 0,632 & 6,556 & 0,754 & 6,671 & 0,726 \\
\hline $\begin{array}{l}9 \\
\text { m 12 salários } \\
\text { mínimos }\end{array}$ & 50 & 6,342 & 0,719 & 6,542 & 0,854 & 6,594 & 0,834 \\
\hline $\begin{array}{l}12 \text { a } 15 \text { salários } \\
\text { mínimos }\end{array}$ & 30 & 6,452 & 0,592 & $\underline{6,424}$ & 0,542 & 6,643 & 1,095 \\
\hline $\begin{array}{l}\text { Mais de 15 } \\
\text { salários }\end{array}$ & 99 & $\underline{6,232}$ & 0,941 & 6,519 & 0,692 & $\underline{6,571}$ & 1,094 \\
\hline
\end{tabular}

Fonte: Os Autores (2016).

Pode-se observar no Quadro acima que, na escala de lealdade, a maior média das notas, 6,662, encontra-se na faixa de 2 a 5 salários mínimos e a menor média, 6,232, está na faixa com mais de 15 salários; porém a diferença das médias é muito pequena, e o desvio padrão da média referente a faixa de mais de 15 salários é o mais alto da escala de Lealdade.

Já na escala de Satisfação, a melhor média, 6,664, está na faixa de renda até 1 salário mínimo e a menor média, 6,424, está na faixa de 12 a 15 salários mínimos. Tanto na escala de Lealdade quanto na de Satisfação, o que pode sugerir é que seja devido ao fato de a Cooperativa oferecer o mesmo tratamento para os clientes com rendas diferentes, que também fazem negócios diferentes e oferecem retornos diferentes para a Cooperativa. Esse fato influencia na Lealdade e Satisfação por parte do cliente maior, que percebe o cliente menor recebendo os mesmos benefícios que os seus, oferecendo uma reciprocidade menor.

Na escala de comportamento Boca a Boca, da mesma forma que na escala de Lealdade, a menor média, 6,571, ficou na faixa de mais de 15 salários, com desvio padrão de 1,094. 0 segundo maior desvio padrão e a maior média ficaram na faixa de 2 a 5 salários mínimos, com desvio padrão de 0,784.

Ao analisarmos a aplicação do modelo e a descrição das médias, em relação à Renda, podese evidenciar, portanto, que, em geral, as menores faixas de renda apresentaram as melhores notas relacionadas a Lealdade, Satisfação e Boca a Boca e que as menores médias encontram-se nas faixas de renda mais elevadas, evidenciando um foco, sob a perspectiva do cooperado, mais adequado ao perfil de baixa renda, possibilitando uma visão alternativa da origem histórica da Cooperativa, cujo intuito inicial era focar em públicos de rendas mais elevadas, como é o caso dos profissionais da saúde, cuja remuneração, no contexto brasileiro, pode ser considerada elevada. 


\section{CONSIDERAÇÕES FINAIS}

Oriunda de um rol analítico mais amplo, sob a perspectiva de segmentações de análise, a presente pesquisa se propôs a expor a análise da experiência em serviços de forma geral, inicialmente, apresentando ainda sua segmentação específica focada na renda dos cooperados da Cooperativa Uniprime.

Sob o escopo geral, em relação à percepção dos cooperados com a experiência em serviços, pode-se compreender que os cooperados consideram alguns fatores como mais relevantes, sendo eles: suas experiências passadas, a variedade dos serviços e a confiança que adquiriu pela Cooperativa. Já em relação à experiência com o produto, evidenciou-se uma necessidade de comparar os produtos da Cooperativa com os de outras instituições e ainda a necessidade de mais produtos além dos que a Cooperativa tem a oferecer. Ainda, apresentou evidências de que, apesar da necessidade do aumento de produtos por parte cooperado, este sente-se bem quando vai à Cooperativa e tem uma impressão positiva desta e também considera que utilizará a cooperativa nos próximos anos e a recomenda a seus familiares, o que comprova os aspectos satisfação e lealdade.

Sob o escopo mais específico, da renda, a percepção dos cooperados em relação a Lealdade, Satisfação e Boca a Boca demonstra que, em geral, as menores faixas de renda apresentaram as melhores notas relacionadas a Lealdade, Satisfação e Boca a Boca e que as menores médias encontram-se nas faixas de renda mais elevadas, evidenciando um foco, sob a perspectiva do cooperado, mais adequado ao perfil de baixa renda, possibilitando uma visão alternativa da origem histórica da Cooperativa, cujo intuito inicial era focar em públicos de rendas mais elevadas, como é o caso dos profissionais da saúde, cuja remuneração no contexto brasileiro pode ser considerada elevada.

Em questões práticas, a presente pesquisa revelou a relação entre a experiência em serviços dos cooperados na geração de satisfação, lealdade e boca a boca do quadro social sob o foco da renda de seus cooperados, permitindo à cooperativa estudada obter uma visão detalhada do ponto de vista do quadro social em relação a seu relacionamento com a Cooperativa.

Tais aspectos auxiliam na percepção do posicionamento estratégico da organização, foco do estudo, contribuindo para que a Cooperativa conheça melhor os anseios de seu quadro social, para poder, assim, elaborar ações de aproximação ou, ainda, ações que venham contribuir com a experiência de serviços dos cooperados com a Cooperativa, de forma mais específica.

A pesquisa ainda contribui nos processos decisórios vinculados aos pontos em que os cooperados demonstram-se insatisfeitos, evidenciando possíveis fragilidades na prestação de serviços ou ainda no portfólio de produtos da Cooperativa, podendo assim exercer de forma ampla o seu objetivo de existência e sua missão de atender às necessidades de seu quadro social e de ser a principal instituição financeira dos seus cooperados.

\section{REFERÊNCIAS}

AGUIAR, E. C.; FARIAS, S. A. O que os olhos veem: a perspectiva do consumidor sobre o significado de cores e iluminação na atmosfera de restaurante centrado na experiência. In: ENCONTRO NACIONAL DA ASSOCIAÇÃO NACIONAL DOS PROGRAMAS DE PÓS-GRADUAÇÃO EM ADMINISTRAÇÃO, 36., 2012, Rio de Janeiro. Anais [...]. Rio de Janeiro: ANPAD, 2012. 
ANDRADE, V. M. Gerenciamento de impressões em serviços de hospitalidade: investigando o servicescape em hotéis com base na metáfora teatral. In: ENCONTRO NACIONAL DA ASSOCIAÇÃO NACIONAL DOS PROGRAMAS DE PÓS-GRADUAÇÃO EM ADMINISTRAÇÃO, 28., 2004, Curitiba. Anais [...]. Curitiba: ANPAD, 2004.

BANCO CENTRAL DO BRASIL (BCB). Dados financeiros. 2015. Disponível em: https://www3.bcb.gov.br/in formes/?wicket:interface=:0:3. Acesso em: 5 dez. 2015.

BELMONTE, S. Sistema de crédito cooperativo avança mesmo em meio à crise. Executivos Financeiros, 12 maio 2016. Disponível em: http://www.executivosfinanceiros.com.br/credito/3031-sistema-de-creditocooperativo-avanca-mesmo-em-meio-a-crise. Acesso em: 20 out. 2017.

BITNER, M. J. Servicescape: the impact of physical surroundings on customers and employees. Journal of Marketing, Chicago, v. 56, n. 2, p. 57-71, 1992.

BRASIL. Lei n. 4.595, de 31 de dezembro de 1964. Dispõe sobre a Política e as Instituições Monetárias, Bancárias e Creditícias, cria o Conselho Monetário Nacional e dá outras providências. Diário Oficial da União, Brasília, 31 jan. 1965. Disponível em: http://www.planalto.gov.br/ccivil_03/leis/L4595.htm. Acesso em: 5 fev. 2016.

BRASIL. Lei n. 5.764, de 16 de dezembro de 1971. Define a Política Nacional de Cooperativismo, institui o regime jurídico das sociedades cooperativas, e dá outras providências. Diário Oficial da União, Brasília, 16 dez. 1971. Disponível em: http://www.normaslegais.com.br/legislacao/lei5764.htm. Acesso em: 24 jan. 2016.

BROWN, J. J.; REIGEN, P. H. Social ties and word of mouth referral behavior. Journal of Consumer Research, Nova York, v. 14, n. 3, p. 350-362, dez. 1987.

BROWN, T. J.; BARRY, T. E.; DACIN, P. A.; GUNST, R. F. Spreading the word: investigating the antecedents of consumers'positive word-of-mouth intentions and behaviors in a retailing context. Journal of Academy of Marketing Science, v. 33, n. 2, p. 123-38, 2005.

CARVALHO, J. L. F.; LIMA, T. R.; MOTTA, P. C. As experiências interativas sociotécnicas com a iluminação de cenário de serviços. In: ENCONTRO NACIONAL DA ASSOCIAÇÃO NACIONAL DOS PROGRAMAS DE PÓSGRADUAÇÃO EM ADMINISTRAÇÃO, 27., 2003, Atibaia. Anais [...]. Atibaia: ANPAD, 2003.

CARVALHO, J. L. F.; MOTTA, P. C. Iluminando cenário de serviços: um exame das funções da luz nas "horas da verdade". In: ENCONTRO NACIONAL DA ASSOCIAÇÃO NACIONAL DOS PROGRAMAS DE PÓS-GRADUAÇÃO EM ADMINISTRAÇÃO, 24., 2000, Costão do Santinho. Anais [...]. Costão do Santinho: ANPAD, 2000.

CARVALHO, J. L. F.; VERGARA, S. C. A fenomenologia e a pesquisa dos espaços de serviços. Revista de Administração de Empresas, São Paulo, v. 42, n. 3, p. 78-91, jul./set. 2002.

CHASE, R. B.; APTE, U. M. A history of research in service operations: what's the big idea? Journal of Operations Management, Dallas, v. 25, n. 2, p. 375-86, 2007.

FERREIRA, F. N. H.; MOREIRA, R. N.; MOURA, S. F. O consumo de experiências em cenários temáticos: um estudo sobre restaurantes de comida japonesa. In: ENCONTRO DE MARKETING DA ANPAD, 2., 2006, Rio de Janeiro. Anais [...]. Rio de Janeiro: ANPAD, 2006.

GREMLER, D. D. Word-of-mouth about service providers: an illustration of theory development in marketing. In: AMA WINTER EDUCATOR'S CONFERENCE, 15., 1994, Chicago. Proceedings [...]. Chicago: American Marketing Association, 1994. p. 62-70. 
HARRISON-WALKER, L. J. The measurement of word-of-mouth communications and an investigation of service quality and customer commitment as potential antecedents. Journal of Service Research, Thousand Oaks, v. 4, n. 1, p. 60-75, ago. 2001.

HEINEKE, J.; DAVIS, M. M. The emergence of service operations management as an academic discipline. Journal of Operations Management, Dallas, v. 25, n. 2, p. 364-74, 2007.

HOLBROOK, M. B.; HIRSCHMAN, E. C. The experiential aspects of consumption: consumer fantasies, feelings, and fun. Journal of Consumer Research, Chicago, v. 9, p. 132-40, set. 1982.

HUBBERT, A. R.; SEHORN, A. G.; BROWN, S. W. Service expectations: the consumer versus the provider. International Journal of Service Industry Management, v. 6, n. 1, p. 6-21, 1995.

INSTITUTO BRASILEIRO DE GEOGRAFIA E ESTATÍTICA (IBGE). Pesquisa anual de serviços. 2016. Disponível em: http://www.ibge.gov.br/home/estatistica/economia/comercioeservico/pas/pas2007_suple_prod_ serv/default.shtm. Acesso em: 6 fev. 2016.

KLAUS, P.; MAKLAN, S. EXQ: a multiple-item scale for assessing service experience. Journal of Service Management, Boston v. 23, n. 1, p. 5-33, 2012.

KLAUS, P.; MAKLAN, S. Toward a better measure of customer experience. International Journal of Marketing Research, London, v. 55, n. 2, p. 227-46, 2013.

MAKLAN, S; KLAUS, P. Customer experience: are we measuring the right things. International Journal of Market Research, London, v. 53, n. 6, p. 771-92, 2011.

MENDONÇA, J. R. C.; BARBOSA, M. L. A.; DURÃO A. F. Fotografias como um recurso de pesquisa em marketing: o uso de métodos visuais no estudo de organizações de serviços. Revista de Administração Contemporânea, Rio de Janeiro, v. 11, n. 3, p. 57-81, jul./set. 2007.

MOURA, F. T.; LUCIAN, R. A experiência extraordinária de um jogo de futebol: a influência do ambiente de serviços e da qualidade percebida na satisfação dos consumidores. In: ENCONTRO NACIONAL DA ASSOCIAÇÃO NACIONAL DOS PROGRAMAS DE PÓS-GRADUAÇÃO EM ADMINISTRAÇÃO, 32., 2008, Rio de Janeiro. Anais [...]. Rio de Janeiro: ANPAD, 2008.

ORGANIZAÇÃO DAS COOPERATIVAS DO BRASIL. Cooperativas de crédito transformam realidades. OCB, 18 out. 2017. Disponível em: http://www.ocb.org.br/noticia/20894/cooperativas-de-credito-transformamrealidades. Acesso em: 20 nov. 2015.

OLIVER, R. L. Satisfaction: a behavioral perspective on the consumer. New York: McGraw Hill, 1997.

PARASURAMAN, A.; ZEITHAML, V. A.; BERRY, L. L. Servqual: a multiple-item scale for measuring consumer perceptions of service quality. Journal of Retailing, Boston, v. 64, n. 1, p. 12-40, 1988.

PARASURAMAN, A.; ZEITHAML, V. A.; MALHOTRA, A. ES-QUAL: a multiple-item scale for assessing electronic service quality. Journal of Service Research, Newcastle Upon Tyne, v. 7, n. 3, p. 213-33, Feb. 2005.

PINE II, J.; GILMORE, J. H. O espetáculo dos negócios: desperte emoções que seduzam os clientes. Sensações intensas determinam o valor de produtos e serviços. 2. ed. Rio de Janeiro: Elsevier, 1999.

PINHO, D. B.; PALHARES, V. M. A. (Org.). O cooperativismo de crédito no Brasil: do século XX ao século XXI. Brasília: Confebrás, 2004. 
PRADO, P. H. M.; SANTOS, R. C. Comprometimento e lealdade: dois conceitos ou duas dimensões de um único conceito? In: ENCONTRO NACIONAL DA ASSOCIAÇÃO NACIONAL DOS PROGRAMAS DE PÓSGRADUAÇÃO EM ADMINISTRAÇÃO, 27., 2003, Atibaia. Anais [...]. Atibaia: ANPAD, 2003.

PULLMAN, M.; GROSS, M. Welcome to your experience: where you can check out anytime you'd like, but you can never leave. Journal of Business and Management, Orange, v. 9, n. 3, p. 215-32, 2003.

REICHHELD, F. F.; MARKEY, Jr. R. G.; HOPTON, C. The loyalty effect: the relationship between loyalty and profits. European Business Journal, Londres, v. 12, n. 3, p. 134-39, 2000.

SCHEMBRI, S. Rationalizing service logic, or understanding service as experience? Marketing Theory, Boston, v. 6, n. 3, p. 381-92, 2006.

SHETH, J. N.; MITTAL, B.; NEWMAN, B. I. Comportamento do cliente: indo além do comportamento do consumidor. São Paulo: Atlas, 2001.

TEIXEIRA, A. K. G.; BARBOSA, M. L. A. O sistema de oferta de restaurantes de alta gastronomia: uma perspectiva sensorial das experiências de consumo. In: ENCONTRO NACIONAL DA ASSOCIAÇÃO NACIONAL DOS PROGRAMAS DE PÓS-GRADUAÇÃO EM ADMINISTRAÇÃO, 32., 2008, Rio de Janeiro. Anais [...]. Rio de Janeiro: ANPAD, 2008.

UNIPRIME CENTRAL. Quem somos. [S.I.]. Disponível em: http://www.uniprimecentral.com.br/cooperativa/ quemsomos. Acesso em: 6 jan. 2016.

VERHOEF, P. C.; LEMON, Katherine N.; PARASURAMAN, A.; ROGGEVEEN, Anne; TSIROS, Michael; SCHLESINGER, Leonard A. Customer experience creation: determinants, dynamics and management strategies. Journal of Retailing, Boston, v. 85, n. 1, p. 31-41, 2009.

VOSS, C.; ROTH, A.; CHASE, R. B. Experience, Service Operations Strategy and Services as Destinations: foundations and exploratory investigation. Production and Operations Management, v. 17, n. 3, p. 24766, 2008.

ZEITHAML, V.; BERRY, L.; PARASURAMAN, A. The behavioral consequences of service quality. Journal of Marketing, Chicago, v. 60, n. 2, p. 31-46, 1996.

\section{Sobre os autores:}

Viviane Sotoriva Cappellesso: Mestre em Gestão de Cooperativas. Gerente Regional Administrativo e Financeiro da cooperativa de crédito Uniprime Pioneira, do PR. E-mail: viviane.4101@uniprimepioneirapr.com.br

June Alisson Westarb Cruz: Doutor e mestre em Administração de Empresas pela Pontifícia Universidade Católica do Paraná (PUCPR). Professor do Programa de Mestrado e Doutorado em Administração na PUCPR. E-mail: junecruz@pucpr.br

Tomas Sparano Martins: Doutor e mestre em Administração de Empresas pela Pontifícia Universidade Católica do Paraná (PUCPR). Professor da área de marketing da Universidade Federal do Paraná. E-mail: tomas.sparano@gmail.com 